\title{
THE EVOLUTION OF COMPARATIVE ADVANTAGE: MEASUREMENT AND WELFARE IMPLICATIONS
}

\author{
Andrei A. Levchenko \\ Jing Zhang \\ Working Paper 16806 \\ http://www.nber.org/papers/w16806
NATIONAL BUREAU OF ECONOMIC RESEARCH
1050 Massachusetts Avenue
Cambridge, MA 02138
February 2011

We are grateful to the editor (Francesco Caselli), two anonymous referees, Costas Arkolakis, Alan Deardor, Chris House, Francesc Ortega, Dmitriy Stolyarov, Linda Tesar, Michael Waugh, Kei-Mu $\mathrm{Yi}$, and participants at numerous seminars and conferences for helpful suggestions, and to Andrew McCallum, Lin Ma, and Nitya Pandalai Nayar for excellent research assistance. The views expressed herein are those of the authors and do not necessarily reflect the views of the National Bureau of Economic Research.

NBER working papers are circulated for discussion and comment purposes. They have not been peerreviewed or been subject to the review by the NBER Board of Directors that accompanies official NBER publications.

(C) 2011 by Andrei A. Levchenko and Jing Zhang. All rights reserved. Short sections of text, not to exceed two paragraphs, may be quoted without explicit permission provided that full credit, including (C) notice, is given to the source. 
The Evolution of Comparative Advantage: Measurement and Welfare Implications Andrei A. Levchenko and Jing Zhang

NBER Working Paper No. 16806

February 2011, Revised October 2014

JEL No. F11,F43,O33,O47

\begin{abstract}
$\underline{\text { ABSTRACT }}$
We estimate productivities at the sector level for 72 countries and 5 decades, and examine how they evolve over time in both developed and developing countries. In both country groups, comparative advantage has become weaker: productivity grew systematically faster in sectors that were initially at greater comparative disadvantage. These changes have had a significant impact on trade volumes and patterns, and a non-negligible welfare impact. In the counterfactual scenario in which each country's comparative advantage remained the same as in the 1960s, and technology in all sectors grew at the same country-specific average rate, trade volumes would be higher, cross-country export patterns more dissimilar, and intra-industry trade lower than in the data. In this counterfactual scenario, welfare is also $1.6 \%$ higher for the median country compared to the baseline. The welfare impact varies greatly across countries, ranging from $-1.1 \%$ to $+4.3 \%$ among OECD countries, and from $-4.6 \%$ to $+41.9 \%$ among non-OECD countries.
\end{abstract}

\author{
Andrei A. Levchenko \\ Department of Economics \\ University of Michigan \\ 611 Tappan Street \\ Ann Arbor, MI 48109 \\ and NBER \\ alev@umich.edu \\ Jing Zhang \\ Research Department \\ Federal Reserve Bank of Chicago \\ 230 S LaSalle Street \\ Chicago, IL 60604 \\ Jing.Zhang@chi.frb.org
}




\section{Introduction}

How does technology evolve over time? This question is important in many contexts, most notably in economic growth and international trade. Much of the economic growth literature focuses on absolute technological differences between countries. In the context of the one-sector model common in this literature, technological progress is unambiguously beneficial. Indeed, one reading of the growth literature is that most of the cross-country income differences are accounted for by technology, broadly construed (Klenow and Rodríguez-Clare 1997, Hall and Jones 1999).

By contrast, the Ricardian tradition in international trade emphasizes relative technological differences as the reason for international exchange and gains from trade. In the presence of multiple industries and comparative advantage, the welfare consequences of technological improvements depend crucially on which sectors experience productivity growth. For instance, it is well known that when productivity growth is biased towards sectors in which a country has a comparative disadvantage, the country and its trading partners may experience a welfare loss, relative to the alternative under which growth is balanced across sectors. Greater relative technological differences lead to larger gains from trade, and thus welfare could be reduced when countries become more similar to each other. This result goes back to at least Hicks (1953), and has been reiterated recently by Samuelson (2004) in the context of productivity growth in developing countries. ${ }^{1}$

To fully account for the impact of technological progress on economic outcomes, we must thus understand not only the evolution of average country-level TFP, but also the evolution of relative technology across sectors. Or, in the vocabulary of international trade, it is important to know what happens to both absolute and comparative advantage. Until now the literature has focused almost exclusively on estimating differences in technology at the country level. This paper examines the evolution of comparative advantage over time and its implications. Using a large-scale industry-level dataset on production and bilateral trade, spanning 72 countries, 19 manufacturing sectors, and 5 decades, we estimate productivity in each country, sector, and decade, and document the changes in comparative advantage between the 1960s and today. We then use these estimates in a multi-sector Ricardian model of production and trade to quantify the implications of changing comparative advantage on global trade patterns and welfare. ${ }^{2}$

Our main results can be summarized as follows. First, we find strong evidence that comparative advantage has become weaker over time. Controlling for the average productivity growth of all sectors in a country, sectors that had a larger initial comparative disadvantage grew sys-

\footnotetext{
${ }^{1}$ Other papers that explore technological change in Ricardian models are, among many others, Jones (1979), Krugman (1979), Brezis, Krugman and Tsiddon (1993), and Hymans and Stafford (1995).

${ }^{2}$ Technically, the term "comparative advantage" refers to the comparison of autarky prices (Deardorff 1980), and thus encompasses all determinants of relative production cost differences. To streamline exposition, this paper uses "comparative advantage" as a short-hand for "relative sectoral productivity differences," i.e., the Ricardian component of comparative advantage.
} 
tematically faster. This effect is present in all time periods, and is similar in magnitude in both developed and developing countries. The speed of convergence in sectoral productivities implied by the estimates is about $18 \%$ per decade.

Second, weakening comparative advantage is important for understanding the evolution of trade volumes and trade patterns. Our quantitative exercise begins by solving the full model under the actually observed pattern of comparative advantage, and computing all the relevant model outcomes under this baseline case. We then compare the baseline to a counterfactual scenario in which each country's sectoral productivities grow at the same average rate observed between the 1960 s and the 2000s, but its comparative advantage remains as it was in the 1960s. Because we allow average productivity to grow, this exercise isolates the role of changes in comparative - as opposed to absolute - advantage.

The baseline matches the average trade/GDP ratios observed in the data well. In the counterfactual of unchanged comparative advantage, however, trade volumes as a share of GDP are $15 \%$ higher in the 2000s, implying that the rise in trade volumes over the past 5 decades would have been even higher had comparative advantage not weakened.

Changes in comparative advantage have had an impact on trade patterns as well. We document that in the data, trade patterns became substantially more similar across countries. In the majority of sectors, the standard deviation of (log) world export shares across countries has fallen significantly between the 1960s and the 2000s. In addition, over the same period there has been a substantial increase in intra-industry trade (measured here by the Grubel-Lloyd index). As our baseline model is implemented on observed trade flows, it matches these two patterns very well. By contrast, the counterfactual experiment in which comparative advantage is fixed implies a much smaller reduction in the dispersion in world export shares, and a much smaller increase in intra-industry trade than observed in the data.

Finally, these changes in comparative advantage had an appreciable welfare impact. In the counterfactual scenario of unchanging comparative advantage, in the 2000s the median country's welfare would be $1.6 \%$ higher than in the baseline. This median welfare impact amounts to nearly $25 \%$ of the median gains from trade relative to autarky implied by the model, which are $6.6 \%$. Moreover, there is a great deal of variation around this average: the percentage difference between welfare under this counterfactual and the baseline ranges from $-1.1 \%$ to $+4.3 \%$ among OECD countries, and from $-4.6 \%$ to $+41.9 \%$ among non-OECD countries. The cross-country dispersion in the welfare impact of changing comparative advantage is similar to the dispersion in the implied gains from trade. Lower average welfare is exactly what theory would predict, given the empirical result that a typical country's comparative advantage has become weaker over this period.

To estimate productivity, the paper extends the methodology developed by Eaton and Kortum (2002) to a multi-sector framework. It is important to emphasize the advantages of our approach 
relative to the standard neoclassical methodology of computing measured TFP. The basic difficulty in directly measuring sectoral TFP in a large sample of countries and over time is the lack of comparable data on real sectoral output and inputs. ${ }^{3}$ By contrast, our procedure uses information on bilateral trade, and thus dramatically expands the set of countries, sectors, and time periods for which productivity can be estimated. We follow the insight of Eaton and Kortum (2002) that trade flows contain information on productivity. Intuitively, if controlling for the typical gravity determinants of trade, a country spends relatively more on domestically produced goods in a particular sector, it is revealed to have either a high relative productivity or a low relative unit cost in that sector. We then use data on factor and intermediate input prices to net out the role of factor costs, yielding an estimate of relative productivity.

In addition, our approach extends the basic multi-sector Eaton-Kortum framework to incorporate many features that are important for reliably estimating underlying technology: multiple factors of production (labor and capital), differences in factor and intermediate input intensities across sectors, a realistic input-output matrix between the sectors, both inter- and intra-sectoral trade, and a non-traded sector. Finally, because our framework allows for international trade driven by both Ricardian and Heckscher-Ohlin forces, it takes explicit account of each country's participation in exports and imports, both of the final output, and of intermediate inputs used in production.

We are not the first to use international trade data to estimate technology parameters. Eaton and Kortum (2002) and Waugh (2010) perform this analysis in a one-sector model at a point in time, an exercise informative of the cross-section of countries' overall TFP but not their comparative advantage. ${ }^{4}$ Shikher $(2011,2012)$ and Costinot, Donaldson and Komunjer (2012) estimate sectoral technology for OECD countries, while Caliendo and Parro (2014) analyze the impact of NAFTA in a multi-sector Eaton-Kortum model. Hsieh and Ossa (2011) examine the global welfare impact of sector-level productivity growth in China between 1993 and 2005, focusing on the uneven growth across sectors. Chor (2010) relates Ricardian productivity differences to observable characteristics of countries, such as institutions and financial development. Relative to existing contributions, we extend the multi-sector approach to a much greater set of countries, and, most importantly, over time. This allows us, for the first time, to examine not only the global cross-section of productivities, but also their evolution over the past 5 decades and the

\footnotetext{
${ }^{3}$ To our knowledge, the most comprehensive database that can be used to measure sectoral TFP on a consistent basis across countries and time is the OECD Structural Analysis (STAN) database. It contains the required information on only 12 developed countries for the period 1970-2008 in the best of cases, but upon closer inspection it turns out that the time and sectoral coverage is poor even in that small set of countries. Appendix A builds measured TFPs using the STAN database, and compares them to our estimates. There is a high positive correlation between the two, providing additional support for the validity of the estimates in this paper.

${ }^{4}$ Finicelli, Pagano and Sbracia (2009) estimate the evolution of overall manufacturing TFP between 1985 and 2002 using a one-sector Eaton and Kortum model.
} 
implications of those changes. While existing papers in this literature employ static models, our quantitative framework features endogenous capital accumulation, and thus permits modeling the joint evolution of comparative advantage and the capital stock. We show that the response of the capital stock to changes in comparative advantage has an appreciable welfare impact.

Changes in productivity at the sector level have received comparatively less attention in the literature. Bernard and Jones (1996a, 1996b) use production data to study convergence of measured TFP in a sample of 15 OECD countries and 8 sectors, while Rodrik (2013) investigates convergence in value added per worker in an expanded sample of countries. Proudman and Redding (2000) and Hausmann and Klinger (2007) examine changes in countries' revealed comparative advantage and how these are related to initial export patterns. Our paper is the first to use a fully specified model of production and trade to estimate changes in underlying TFP. In addition, we greatly expand the sample of countries and years relative to these studies, and use our quantitative framework to compute the impact of the estimated changes in comparative advantage on trade volumes, trade patterns, and welfare.

Our paper is also related to the literature that documents the time evolution of diversification indices, be it of production (e.g. Imbs and Wacziarg 2003), or trade (e.g. Carrère, Cadot and Strauss-Kahn 2011). These studies typically find that countries have a tendency to diversify their production and exports as they grow, at least until they become quite developed. Our findings of weakening comparative advantage are consistent with greater diversification, and hence provide a structural interpretation for the evolution of these indices. ${ }^{5}$

The rest of the paper is organized as follows. Section 2 lays out the theoretical framework. Section 3 presents the estimation procedure and the data. Section 4 describes the patterns of the evolution of comparative advantage over time, and presents the main econometric results of the paper on relative convergence. Section 5 examines the quantitative implications of the observed evolution of comparative advantage. Section 6 concludes.

\section{Theoretical Framework}

The world is comprised of $N$ countries and $J+1$ sectors. Each sector produces a continuum of goods. The first $J$ sectors are tradeable subject to trade costs, and sector $(J+1)$ is nontradeable. There are two factors of production, labor and capital. Both are mobile across sectors and immobile across countries. Trade is balanced each period, and thus we abstract from international asset markets. All agents have perfect foresight and all markets are competitive.

\footnotetext{
${ }^{5}$ Our paper is also related to the literature on international technology diffusion, surveyed by Keller (2004). While we document large and systematic changes in technology over time, our approach is, for now, silent on the mechanisms behind these changes. Section 4.3 relates our empirical results to the theoretical literature on technology adoption and diffusion.
} 


\section{$2.1 \quad$ Households}

In period $t=0$, the representative household in country $n$ is endowed with capital $K_{n 0}$ and labor $L_{n 0}$. Each period, the household saves an exogenous fraction $s_{n t}$ of its current income (as in Solow 1956, Swan 1956), investing it into next period's capital, and consumes the remaining fraction $1-s_{n t}$. The saving rates are country-specific and time-varying. ${ }^{6}$

Period utility of the representative consumer in country $n$ is given by $U\left(C_{n t}\right)$, where $C_{n t}$ denotes aggregate consumption in country $n$ and period $t$. The function $U(\cdot)$ satisfies all the usual regularity conditions. The flow budget constraint of the household in period $t$ is given by

$$
P_{n t}\left(C_{n t}+I_{n t}\right)=P_{n t} Y_{n t}=w_{n t} L_{n t}+r_{n t} K_{n t},
$$

where $P_{n t}$ is the price of aggregate consumption, $I_{n t}$ is flow saving/investment, $Y_{n t}$ is aggregate final output, $K_{n t}$ is the capital stock, $L_{n t}$ is the effective labor endowment, and $w_{n t}$ and $r_{n t}$ are the wage rate and the rental return to capital, respectively. The budget constraint implicitly imposes that international trade is balanced in each period. Since investment $I_{n t}$ is simply $s_{n t} Y_{n t}$, the law of motion for capital is given by

$$
K_{n t+1}=\left(1-\delta_{n t}\right) K_{n t}+s_{n t} Y_{n t},
$$

where $\delta_{n t}$ is the country-specific and time-varying depreciation rate.

The aggregate final output $Y_{n t}$ is an aggregate of sectoral composite goods:

$$
Y_{n t}=\left(\sum_{j=1}^{J} \omega_{j}^{\frac{1}{\eta}}\left(Y_{n t}^{j}\right)^{\frac{\eta-1}{\eta}}\right)^{\frac{\eta}{\eta-1} \xi_{n t}}\left(Y_{n t}^{J+1}\right)^{1-\xi_{n t}}
$$

where $Y_{n t}^{j}$ is the composite good in tradeable sector $j$, and $Y_{n t}^{J+1}$ is the nontradeable-sector composite good. The parameter $\xi_{n t}$ is thus the Cobb-Douglas weight on the tradeable sector composite good, $\eta$ is the elasticity of substitution between the tradeable sectors, and $\omega_{j}$ is the taste parameter for tradeable sector $j$. The expenditure share on tradeables $\xi_{n t}$ varies over time as well as across countries, to capture in a reduced-form way the positive relationship between income and the non-tradeable consumption share observed in the data. The aggregate (consumption)

\footnotetext{
${ }^{6}$ The variation in $s_{n t}$ is meant to capture the influence of demographics, economic growth rates, market frictions, and distortions or subsidies to savings and/or investment due to government policy, or other underlying fundamental differences across countries and over time.
} 
price index in country $n$ and period $t$ is thus:

$$
P_{n t}=B_{n}\left(\sum_{j=1}^{J} \omega_{j}\left(p_{n t}^{j}\right)^{1-\eta}\right)^{\frac{1}{1-\eta} \xi_{n t}}\left(p_{n t}^{J+1}\right)^{1-\xi_{n t}}
$$

where $B_{n}=\xi_{n t}^{-\xi_{n t}}\left(1-\xi_{n t}\right)^{-\left(1-\xi_{n t}\right)}$ and $p_{n t}^{j}$ is the price of the sector $j$ composite.

\section{$2.2 \quad$ Firms}

Output in each sector $j$ and country $n$ and period $t$ is produced using a CES production function that aggregates a continuum of varieties $q \in[0,1]$ unique to each sector:

$$
Q_{n t}^{j}=\left[\int_{0}^{1} Q_{n t}^{j}(q)^{\frac{\varepsilon-1}{\varepsilon}} d q\right]^{\frac{\varepsilon}{\varepsilon-1}}
$$

where $\varepsilon$ denotes the elasticity of substitution across varieties $q, Q_{n t}^{j}$ is the total sector $j$ output in country $n$, and $Q_{n t}^{j}(q)$ is the amount of variety $q$ that is used in production. It is well known that the price of sector $j$ 's output is given by:

$$
p_{n t}^{j}=\left[\int_{0}^{1} p_{n t}^{j}(q)^{1-\varepsilon} d q\right]^{\frac{1}{1-\varepsilon}}
$$

where $p_{n t}^{j}(q)$ is the price of variety $q$ in sector $j$ and country $n$.

The production function of each sectoral variety $q$ is:

$$
y_{n t}^{j}(q)=z_{n t}^{j}(q)\left(k_{n t}^{j}(q)^{1-\alpha_{j}} l_{n t}^{j}(q)^{\alpha_{j}}\right)^{\beta_{j}}\left(\prod_{j^{\prime}=1}^{J+1} m_{n t}^{j^{\prime} j}(q)^{\gamma_{j^{\prime} j}}\right)^{1-\beta_{j}},
$$

where $z_{n t}^{j}(q)$ denotes variety-specific productivity, $k_{n t}^{j}(q)$ and $l_{n t}^{j}(q)$ denote inputs of capital and labor, and $m_{n t}^{j^{\prime} j}$ denotes the intermediate input from sector $j^{\prime}$ used in producing sector- $j$ goods. The value-added based labor intensity is given by $\alpha_{j}$, while the share of value added in total output is given by $\beta_{j}$. Both of these vary by sector. The weights on inputs from other sectors, $\gamma_{j^{\prime} j}$, vary by output industry $j$ as well as input industry $j^{\prime}$.

Productivity $z_{n t}^{j}(q)$ for each $q \in[0,1]$ in each sector $j$ and period $t$ is equally available to all agents in country $n$, and product and factor markets are perfectly competitive. Following Eaton and Kortum (2002, henceforth EK), the productivity draw $z_{n t}^{j}(q)$ is random and comes from the Fréchet distribution with the cumulative distribution function

$$
F_{n t}^{j}(z)=e^{-T_{n t}^{j} z^{-\theta}}
$$


In this distribution, the absolute advantage term $T_{n t}^{j}$ varies by country, sector, and time, with higher values of $T_{n t}^{j}$ implying higher average productivity draws in sector $j$ in country $n$ and period $t$. The parameter $\theta$ captures dispersion, with larger values of $\theta$ implying smaller dispersion in draws.

It will be convenient to define the cost of an "input bundle" faced by sector $j$ producers in country $n$ :

$$
c_{n t}^{j}=\left(w_{n t}^{\alpha_{j}} r_{n t}^{1-\alpha_{j}}\right)^{\beta_{j}}\left(\prod_{j^{\prime}=1}^{J+1}\left(p_{n t}^{j^{\prime}}\right)^{\gamma_{j^{\prime} j}}\right)^{1-\beta_{j}} .
$$

Then, producing one unit of good $q$ in sector $j$ in country $n$ requires $\frac{1}{z_{n t}^{j}(q)}$ input bundles, and thus the cost of producing one unit of good $q$ is $c_{n t}^{j} / z_{n t}^{j}(q)$.

International trade is subject to iceberg costs: in order for one unit of good $q$ produced in sector $j$ to arrive in country $n$ from country $i$ in period $t, d_{\text {nit }}^{j}>1$ units of the good must be shipped. We normalize $d_{n n t}^{j}=1$ for each country $n$ and period $t$ in each tradeable sector $j$. Note that the trade costs will vary by destination pair, by sector, and time, and need not be directionally symmetric: $d_{n i t}^{j}$ need not equal $d_{i n t}^{j}$. Under perfect competition, the price at which country $i$ can supply tradeable good $q$ in sector $j$ to country $n$ is equal to:

$$
p_{n i t}^{j}(q)=\left(\frac{c_{i t}^{j}}{z_{i t}^{j}(q)}\right) d_{n i t}^{j} .
$$

Buyers of each good $q$ in tradeable sector $j$ in country $n$ and period $t$ will select to buy from the cheapest source country. Thus, the price actually paid for this good in country $n$ will be:

$$
p_{n t}^{j}(q)=\min _{i=1, \ldots, N}\left\{p_{n i t}^{j}(q)\right\} .
$$

Following the standard EK approach, define the "multilateral resistance" term

$$
\Phi_{n t}^{j}=\sum_{i=1}^{N} T_{i t}^{j}\left(c_{i t}^{j} d_{n i t}^{j}\right)^{-\theta} .
$$

This value summarizes, for country $n$ and time $t$, the access to production technologies in sector $j$. Its value will be higher if in sector $j$, country $n$ 's trading partners have high productivity $\left(T_{i t}^{j}\right)$ or low costs $\left(c_{i t}^{j}\right)$. It will also be higher if the trade costs that country $n$ faces in this sector are low. Standard steps lead to the familiar result that the probability of importing good $q$ in sector $j$ from country $i$ in period $t, \pi_{n i t}^{j}$, is equal to the share of total spending on goods coming from 
country $i, X_{n i t}^{j} / X_{n t}^{j}$, and is given by:

$$
\frac{X_{n i t}^{j}}{X_{n t}^{j}}=\pi_{n i t}^{j}=\frac{T_{i t}^{j}\left(c_{i t}^{j} d_{n i t}^{j}\right)^{-\theta}}{\Phi_{n t}^{j}}
$$

In addition, the price of good $j$ in country $n$ and period $t$ is simply

$$
p_{n t}^{j}=\Gamma\left(\Phi_{n t}^{j}\right)^{-\frac{1}{\theta}}
$$

where $\Gamma=\left[\Gamma\left(\frac{\theta+1-\varepsilon}{\theta}\right)\right]^{\frac{1}{1-\varepsilon}}$, and $\boldsymbol{\Gamma}$ is the Gamma function.

\subsection{Equilibrium}

The competitive equilibrium of this model world economy consists of sequences of prices, allocation rules, and trade shares such that (i) given the prices, all firms' inputs satisfy the first-order conditions, and their output is given by the production function; (ii) the households' aggregate consumption and investment decisions are consistent with the exogenous saving rates, and their sectoral demands satisfy the first order conditions given the prices; (iii) the prices ensure the market clearing conditions for labor, capital, tradeable goods and nontradeable goods; (iv) trade shares ensure balanced trade for each country.

The set of prices includes the wage rate $w_{n t}$, the rental rate $r_{n t}$, the sectoral prices $\left\{p_{n t}^{j}\right\}_{j=1}^{J+1}$, and the aggregate price $P_{n t}$ in each country $n$ and period $t$. The allocation rules include aggregate consumption $C_{n t}$, investment $I_{n t}$, capital $K_{n t}$, the capital and labor allocation across sectors $\left\{K_{n t}^{j}, L_{n t}^{j}\right\}_{j=1}^{J+1}$, final demand $\left\{Y_{n t}^{j}\right\}_{j=1}^{J+1}$, and total demand $\left\{Q_{n t}^{j}\right\}_{j=1}^{J+1}$ (both final and intermediate goods) for each sector. The trade shares include the expenditure shares $\pi_{n i t}^{j}$ in country $n$ on goods coming from country $i$ in sector $j$.

\section{Characterization of Equilibrium}

Given the set of prices $\left\{w_{n t}, r_{n t}, P_{n t},\left\{p_{n t}^{j}\right\}_{j=1}^{J+1}\right\}_{n=1}^{N}$, we first characterize the optimal sectoral allocations from final demand. Consumers maximize utility subject to the budget constraint (1), (2), and (3). The first order conditions associated with this optimization problem imply the following final demand across sectors:

$$
p_{n t}^{j} Y_{n t}^{j}=\xi_{n t}\left(w_{n t} L_{n t}+r_{n t} K_{n t}\right) \frac{\omega_{j}\left(p_{n t}^{j}\right)^{1-\eta}}{\sum_{k=1}^{J} \omega_{k}\left(p_{n t}^{k}\right)^{1-\eta}}, \text { for all } j=\{1, . ., J\}
$$

and

$$
p_{n t}^{J+1} Y_{n t}^{J+1}=\left(1-\xi_{n t}\right)\left(w_{n t} L_{n t}+r_{n t} K_{n t}\right)
$$


We next characterize the production and factor allocations across the world. Let $Q_{n t}^{j}$ denote the total sectoral demand in country $n$ and sector $j$ in period $t . Q_{n t}^{j}$ is used for both final demand and intermediate inputs in domestic production of all sectors. That is,

$$
p_{n t}^{j} Q_{n t}^{j}=p_{n t}^{j} Y_{n t}^{j}+\sum_{j^{\prime}=1}^{J}\left(1-\beta_{j^{\prime}}\right) \gamma_{j j^{\prime}}\left(\sum_{i=1}^{N} \pi_{i n t}^{j^{\prime}} p_{i t}^{j^{\prime}} Q_{i t}^{j^{\prime}}\right)+\left(1-\beta_{J+1}\right) \gamma_{j, J+1} p_{n t}^{J+1} Q_{n t}^{J+1}
$$

Total expenditure in sector $j=1, \ldots, J+1$ of country $n, p_{n t}^{j} Q_{n t}^{j}$, is the sum of (i) domestic final consumption expenditure $p_{n t}^{j} Y_{n t}^{j}$; (ii) expenditure on sector $j$ goods as intermediate inputs in all the traded sectors $\sum_{j^{\prime}=1}^{J}\left(1-\beta_{j^{\prime}}\right) \gamma_{j j^{\prime}}\left(\sum_{i=1}^{N} \pi_{i n t}^{j^{\prime}} p_{i t}^{j^{\prime}} Q_{i t}^{j^{\prime}}\right)$, and (iii) expenditure on intermediate inputs from sector $j$ in the domestic non-traded sector $\left(1-\beta_{J+1}\right) \gamma_{j, J+1} p_{n t}^{J+1} Q_{n t}^{J+1}$. These market clearing conditions summarize the two important features of the world economy captured by our model: complex international production linkages, as much of world trade is in intermediate inputs, and a good crosses borders multiple times before being consumed (Hummels, Ishii and Yi 2001); and two-way input linkages between the tradeable and the nontradeable sectors.

In each tradeable sector $j$, some goods $q$ are imported from abroad and some goods $q$ are exported to the rest of the world. Country n's exports in sector $j$ and period $t$ are given by $E X_{n t}^{j}=$ $\sum_{i=1}^{N} \mathbb{I}_{i \neq n} \pi_{i n t}^{j} p_{i t}^{j} Q_{i t}^{j}$, and its imports in sector $j$ are given by $I M_{n t}^{j}=\sum_{i=1}^{N} \mathbb{I}_{i \neq n} \pi_{n i t}^{j} p_{n t}^{j} Q_{n t}^{j}$, where $\mathbb{I}_{i \neq n}$ is the indicator function. The total exports of country $n$ are then $E X_{n t}=\sum_{j=1}^{J} E X_{n t}^{j}$, and total imports are $I M_{n t}=\sum_{j=1}^{J} I M_{n t}^{j}$. Trade balance requires that for every country $n$ and time $t, E X_{n t}-I M_{n t}=0$.

We now characterize the factor allocations across sectors. The total production revenue in tradeable sector $j$ in country $n$ and period $t$ is given by $\sum_{i=1}^{N} \pi_{i n t}^{j} p_{i t}^{j} Q_{i t}^{j}$. The optimal sectoral factor allocations in country $n$ and tradeable sector $j$ in period $t$ must thus satisfy

$$
\sum_{i=1}^{N} \pi_{i n t}^{j} p_{i t}^{j} Q_{i t}^{j}=\frac{w_{n t} L_{n t}^{j}}{\alpha_{j} \beta_{j}}=\frac{r_{n t} K_{n t}^{j}}{\left(1-\alpha_{j}\right) \beta_{j}}
$$

For the nontradeable sector $J+1$, the optimal factor allocations in country $n$ are simply given by

$$
p_{n t}^{J+1} Q_{n t}^{J+1}=\frac{w_{n t} L_{n t}^{J+1}}{\alpha_{J+1} \beta_{J+1}}=\frac{r_{n t} K_{n t}^{J+1}}{\left(1-\alpha_{J+1}\right) \beta_{J+1}} .
$$

Finally, the feasibility conditions for factors are given by, for any $n$,

$$
\sum_{j=1}^{J+1} L_{n t}^{j}=L_{n t} \text { and } \sum_{j=1}^{J+1} K_{n t}^{j}=K_{n t}
$$

Given all of the model parameters, factor endowments, trade costs, and productivities, the model is solved using the algorithm described in Appendix B. 


\section{Estimating Model Parameters}

This section estimates the sector-level technology parameters $T_{n t}^{j}$ for a large set of countries and 5 decades in three steps. First, we estimate the technology parameters in the tradeable sectors relative to the U.S. using data on sectoral output and bilateral trade. The procedure relies on fitting a structural gravity equation implied by the model. This step also produces estimates of bilateral trade costs at the sector level over time. Second, we estimate the technology parameters in the tradeable sectors for the U.S. This procedure requires directly measuring sectoral TFP using data on real output and inputs, and then correcting measured TFP for selection due to trade. The taste parameters for all tradeable sectors $\omega_{j}$ are also calibrated in this step. Third, the nontradeable technology is calibrated to match the PPP income per capita in the data.

The calibration of the remaining parameters is more straightforward. Some parameters $\alpha_{j}, \beta_{j}, \gamma_{j^{\prime} j}, s_{n t}, \xi_{n t}, L_{n t}$, and $K_{n t}$ - come directly from the data. For a small number of parameters $-\theta, \eta$, and $\varepsilon-$ we take values estimated elsewhere in the literature. Sections 3.1 and 3.2 describe the estimation of sectoral technology, and Section 3.3 discusses the data sources used in the estimation as well as the choice of the other parameters.

\subsection{Tradeable Sector Relative Technology}

Following the standard EK approach, first divide trade shares by their domestic counterpart:

$$
\frac{\pi_{n i t}^{j}}{\pi_{n n t}^{j}}=\frac{X_{n i t}^{j}}{X_{n n t}^{j}}=\frac{T_{i t}^{j}\left(c_{i t}^{j} d_{n i t}^{j}\right)^{-\theta}}{T_{n t}^{j}\left(c_{n t}^{j}\right)^{-\theta}}
$$

which in logs becomes:

$$
\ln \left(\frac{X_{n i t}^{j}}{X_{n n t}^{j}}\right)=\ln \left(T_{i t}^{j}\left(c_{i t}^{j}\right)^{-\theta}\right)-\ln \left(T_{n t}^{j}\left(c_{n t}^{j}\right)^{-\theta}\right)-\theta \ln d_{n i t}^{j} .
$$

Let the $(\log )$ iceberg costs be given by the following expression:

$$
\ln d_{n i t}^{j}=d_{k, t}^{j}+b_{n i t}^{j}+\mathrm{CU}_{n i t}^{j}+\mathrm{RTA}_{n i t}^{j}+e x_{i t}^{j}+\nu_{n i t}^{j},
$$

where $d_{k, t}^{j}$ is the contribution to trade costs of the distance between $n$ and $i$ being in a certain interval (indexed by $k$ ). Following EK, we set the distance intervals, in miles, to [0, 350], [350, 750], [750, 1500], [1500, 3000], [3000, 6000], [6000, maximum). Additional variables are whether

the two countries share a common border (which changes the trade costs by $b_{n i t}^{j}$ ), belong to a currency union $\left(\mathrm{CU}_{n i t}^{j}\right)$, or to a regional trade agreement $\left(\mathrm{RTA}_{n i t}^{j}\right)$. We include an exporter fixed effect $e x_{i t}^{j}$ following Waugh (2010), who shows that the exporter fixed effect specification does a 
better job at matching the patterns in both country incomes and observed price levels. Finally, there is an error term $\nu_{n i t}^{j}$. Section 4.4 assesses the robustness of the estimates to both the set of geographic controls and the assumption of the exporter fixed effect in $d_{n i t}^{j}$. Note that all the variables have a time subscript and a sector superscript $j$ : all the trade cost proxy variables affect true iceberg trade costs $d_{n i t}^{j}$ differentially across both time periods and sectors. There is a range of evidence that trade volumes at sector level vary in their sensitivity to distance or common border (see, among many others, Do and Levchenko 2007, Berthelon and Freund 2008).

This leads to the following final estimating equation:

$$
\begin{aligned}
\ln \left(\frac{X_{n i t}^{j}}{X_{n n t}^{j}}\right)= & \underbrace{\ln \left(T_{i t}^{j}\left(c_{i t}^{j}\right)^{-\theta}\right)-\theta e x_{i t}^{j}}_{\text {Exporter Fixed Effect }} \underbrace{-\ln \left(T_{n t}^{j}\left(c_{n t}^{j}\right)^{-\theta}\right)}_{\text {Importer Fixed Effect }} \\
& \underbrace{-\theta d_{k, t}^{j}-\theta b_{n i t}^{j}-\theta \mathrm{CU}_{n i t}^{j}-\theta \mathrm{RTA}_{n i t}^{j}}_{\text {Bilateral Observables }} \underbrace{-\theta \nu_{n i t}^{j}}_{\text {Error Term }} .
\end{aligned}
$$

This specification is estimated for each sector and decade separately, allowing for complete flexibility in how the coefficients vary both across sectors and over time. Estimating this relationship will thus yield, for each country and time period, an estimate of its technology-cum-unit-cost term in each sector $j, T_{n t}^{j}\left(c_{n t}^{j}\right)^{-\theta}$, which is obtained by exponentiating the importer fixed effect. The available degrees of freedom imply that these estimates are of each country's $T_{n t}^{j}\left(c_{n t}^{j}\right)^{-\theta}$ relative to a reference country, which in our estimation is the United States. We denote this estimated value by $S_{n t}^{j}$ :

$$
S_{n t}^{j}=\frac{T_{n t}^{j}}{T_{u s t}^{j}}\left(\frac{c_{n t}^{j}}{c_{u s t}^{j}}\right)^{-\theta}
$$

where the subscript us denotes the United States. It is immediate from this expression that estimation delivers a convolution of technology parameters $T_{n t}^{j}$ and cost parameters $c_{n t}^{j}$. Both will of course affect trade volumes, but we would like to extract technology $T_{n t}^{j}$ from these estimates. In order to do that, we follow the approach of Shikher (2012). In particular, for each country $n$, the share of total spending going to home-produced goods is given by

$$
\frac{X_{n n t}^{j}}{X_{n t}^{j}}=T_{n t}^{j}\left(\frac{\Gamma c_{n t}^{j}}{p_{n t}^{j}}\right)^{-\theta}
$$

Dividing by its U.S. counterpart yields:

$$
\frac{X_{n n t}^{j} / X_{n t}^{j}}{X_{u s, u s, t}^{j} / X_{u s t}^{j}}=\frac{T_{n t}^{j}}{T_{u s t}^{j}}\left(\frac{c_{n t}^{j}}{c_{u s t}^{j}} \frac{p_{u s t}^{j}}{p_{n t}^{j}}\right)^{-\theta}=S_{n t}^{j}\left(\frac{p_{u s t}^{j}}{p_{n t}^{j}}\right)^{-\theta},
$$


and thus the ratio of price levels in sector $j$ relative to the U.S. becomes:

$$
\frac{p_{n t}^{j}}{p_{u s t}^{j}}=\left(\frac{X_{n n t}^{j} / X_{n t}^{j}}{X_{u s, u s, t}^{j} / X_{u s t}^{j}} \frac{1}{S_{n t}^{j}}\right)^{\frac{1}{\theta}} .
$$

The entire right-hand side of this expression is either observable or estimated. Thus, we can impute the price levels relative to the U.S. in each country and each tradeable sector.

The cost of the input bundles relative to the U.S. can be written as:

$$
\frac{c_{n t}^{j}}{c_{u s t}^{j}}=\left(\frac{w_{n t}}{w_{u s t}}\right)^{\alpha_{j} \beta_{j}}\left(\frac{r_{n t}}{r_{u s t}}\right)^{\left(1-\alpha_{j}\right) \beta_{j}}\left(\prod_{j^{\prime}=1}^{J}\left(\frac{p_{n t}^{j^{\prime}}}{p_{u s t}^{j^{\prime}}}\right)^{\gamma_{j^{\prime} j}}\right)^{1-\beta_{j}}\left(\frac{p_{n t}^{J+1}}{p_{u s t}^{J+1}}\right)^{\gamma_{J+1, j}\left(1-\beta_{j}\right)} .
$$

Using information on relative wages, returns to capital, price in each tradeable sector from (7), and the nontradeable sector price relative to the U.S., we can thus impute the costs of the input bundles relative to the U.S. in each country and each sector. Armed with those values, it is straightforward to back out the relative technology parameters:

$$
\frac{T_{n t}^{j}}{T_{u s t}^{j}}=S_{n t}^{j}\left(\frac{c_{n t}^{j}}{c_{u s t}^{j}}\right)^{\theta}
$$

This approach bears a close affinity to development accounting (see, e.g. Caselli 2005). Development accounting starts with an observable variable to be accounted for (real per capita income), and employs other observables - physical capital, human capital, health endowments, etc. - to absorb as much cross-country variation in the variable of interest as possible. The unexplained remainder is called TFP. In our procedure, the outcome variable of interest is not income but $S_{n t}^{j}$. Intuitively, if, controlling for the typical gravity determinants of trade, a country spends relatively more on domestically produced goods in a particular sector - $S_{n t}^{j}$ is high - it is revealed to have either a high relative productivity or a low relative factor and input cost in that sector. Just as in development accounting, we then use measured factor and intermediate input prices to net out the role of factor and input costs, yielding an estimate of relative productivity as a residual. ${ }^{7}$ As in development accounting, to reach reliable estimates it is important to net out the impact of as many observables as possible. Thus, our model features human and physical capital and sophisticated input linkages, including explicit nontradeable inputs. To accurately reflect sectoral factor and input cost differences, production function parameters are sector-specific.

\footnotetext{
${ }^{7}$ Since our approach uses factor prices rather than factor endowments, it is closer in spirit to the "dual" approach to growth accounting (e.g. Hsieh 2002).
} 


\subsection{Complete Estimation}

So far we have estimated the levels of technology of the tradeable sectors relative to the United States. To complete our estimation, we still need to find (i) the levels of $T$ for the tradeable sectors in the United States; (ii) the taste parameters $\omega_{j}$, and (iii) the nontradeable technology levels for all countries.

To obtain (i), we use the NBER-CES Manufacturing Industry Database for the U.S. (Bartelsman and Gray 1996). We start by measuring the observed TFP levels for the tradeable sectors in the U.S.. The form of the production function gives

$$
\ln Z_{u s t}^{j}=\ln \Lambda_{u s t}^{j}+\beta_{j} \alpha_{j} \ln L_{u s t}^{j}+\beta_{j}\left(1-\alpha_{j}\right) \ln K_{u s t}^{j}+\left(1-\beta_{j}\right) \sum_{j^{\prime}=1}^{J+1} \gamma_{j^{\prime} j} \ln M_{u s t}^{j^{\prime} j},
$$

where $\Lambda^{j}$ denotes the measured TFP in sector $j, Z^{j}$ denotes the output, $L^{j}$ denotes the labor input, $K^{j}$ denotes the capital input, and $M^{j^{\prime} j}$ denotes the intermediate input from sector $j^{\prime}$. The NBER-CES Manufacturing Industry Database offers information on output, and inputs of labor, capital, and intermediates, along with deflators for each. Thus, we can estimate the observed TFP level for each manufacturing tradeable sector using the above equation.

If the United States were a closed economy, the observed TFP level for sector $j$ would be given by $\Lambda_{u s t}^{j}=\left(T_{u s t}^{j}\right)^{\frac{1}{\theta}}$. In the open economies, the goods with inefficient domestic productivity draws will not be produced and will be imported instead. Thus, international trade and competition introduce selection in the observed TFP level, as demonstrated by Finicelli, Pagano and Sbracia (2013). We thus use the model to back out the true level of $T_{u s t}^{j}$ of each tradeable sector in the United States. Here we follow Finicelli et al. (2013) and use the following relationship:

$$
\left(\Lambda_{u s t}^{j}\right)^{\theta}=T_{u s t}^{j}+\sum_{i \neq u s} T_{i t}^{j}\left(\frac{c_{i t}^{j} d_{u s i t}^{j}}{c_{u s t}^{j}}\right)^{-\theta}
$$

Thus, we have

$$
\left(\Lambda_{u s t}^{j}\right)^{\theta}=T_{u s t}^{j}\left[1+\sum_{i \neq u s} \frac{T_{i t}^{j}}{T_{u s t}^{j}}\left(\frac{c_{i t}^{j} d_{u s i t}^{j}}{c_{u s t}^{j}}\right)^{-\theta}\right]=T_{u s t}^{j}\left[1+\sum_{i \neq u s} S_{i t}^{j}\left(d_{u s i t}^{j}\right)^{-\theta}\right] .
$$

This equation can be solved for underlying technology parameters $T_{u s t}^{j}$ in the U.S., given estimated observed TFP $\Lambda_{u s t}^{j}$, and all the $S_{i t}^{j}$ 's and $d_{u s i t}^{j}$ 's estimated in the previous subsection.

To estimate the taste parameters $\left\{\omega_{j}\right\}_{j=1}^{J}$, we use information on final consumption shares in the tradeable sectors in the U.S.. We start with a guess of $\left\{\omega_{j}\right\}_{j=1}^{J}$ and find sectoral prices $p_{n t}^{j \prime}$ as follows. For an initial guess of sectoral prices, we compute the tradeable sector aggregate price and 
the nontradeable sector price using the data on the relative prices of nontradeables to tradeables. Using these prices, we calculate sectoral unit costs and $\Phi_{n t}^{j}$ 's, and update prices according to equation (4), iterating until the prices converge. We then update the taste parameters according to equation (5), using the data on final sectoral expenditure shares in the U.S.. We normalize the vector of $\omega_{j}$ 's to have a sum of one, and repeat the above procedure until the values for the taste parameters converge. This procedure is carried out on the 2000s, and the resulting values applied to the entire period.

Finally, we calibrate the nontradeable sector TFP in each country to match the observed PPP-adjusted income per capita. This step involves solving the model with an initial guess of $\left\{T_{n t}^{J+1}\right\}_{n=1}^{N}$ and iteratively updating it until the model-implied income per capita adjusted for the aggregate price converges to that in the data for each country and each decade. This calibration approach guarantees that the model produces a cross-country income distribution identical to the data for each decade.

\subsection{Data Description and Implementation}

We assemble data on production and trade for a sample of up to 72 countries, 19 manufacturing sectors, and spanning 5 decades, from the 1960s to the 2000s. Production data come from the 2009 UNIDO Industrial Statistics Database, which reports output, value added, employment, and wage bills at roughly 2-digit ISIC Revision 3 level of disaggregation for the period 1962-2007 in the best of cases. The corresponding trade data come from the COMTRADE database compiled by the United Nations. The trade data are collected at the 4-digit SITC level, and aggregated up to the 2-digit ISIC level using a concordance developed by the authors. Production and trade data were extensively checked for quality, and a number of countries were discarded due to poor data quality. In addition, in less than $5 \%$ of country-year-sector observations, the reported total output was below total exports, and thus had to be imputed based on earlier values and the evolution of exports.

The distance and common border variables are obtained from the comprehensive geography database compiled by CEPII. Information on regional trade agreements comes from the RTA database maintained by the WTO. The currency union indicator comes from Rose (2004), and was updated for the post-2000 period using publicly available information (such as the membership in the Euro area, and the dollarization of Ecuador and El Salvador).

In addition to providing data on output for gravity estimation, the UNIDO data are used to estimate production function parameters $\alpha_{j}$ and $\beta_{j}$. To compute $\alpha_{j}$ for each sector, we calculate the share of the total wage bill in value added, and take a simple median across countries (taking the mean yields essentially the same results). To compute $\beta_{j}$, we take the median of value added 
divided by total output.

The intermediate input coefficients $\gamma_{j^{\prime} j}$ are obtained from the Direct Requirements Table for the United States. We use the 1997 Benchmark Detailed Make and Use Tables (covering approximately 500 distinct sectors), as well as a concordance to the ISIC Revision 3 classification to build a Direct Requirements Table at the 2-digit ISIC level. The Direct Requirements Table gives the value of the intermediate input in row $j$ l required to produce one dollar of final output in column $j$. Thus, it is the direct counterpart of the input coefficients $\gamma_{j^{\prime} j}$. In addition, we use the U.S. I-O matrix to obtain the shares of total final consumption expenditure going to each sector, which we use to pin down taste parameters $\omega_{j}$ in traded sectors $1, \ldots, J$; as well as $\alpha_{J+1}$ and $\beta_{J+1}$ in the nontradeable sector, which cannot be obtained from UNIDO. ${ }^{8}$ The baseline analysis assumes $\alpha_{j}, \beta_{j}$, and $\gamma_{j^{\prime} j}$ to be the same in all countries. Section 4.4 assesses the robustness of the productivity estimates to allowing these parameters to vary by country.

The total labor force in each country, $L_{n t}$, and the total capital stock, $K_{n t}$, are obtained from the Penn World Tables 8.0 (PWT8.0). The labor endowment $L_{n t}$ is corrected for human capital (schooling) differences using the human capital variable available in PWT8.0. Thus, the wage $w_{n t}$ captures the relative price of an efficiency unit of labor. The capital series $K_{n t}$ is available directly in PWT8.0. The saving/investment rate $s_{n t}$ is calculated based on the Penn World Tables as the implied decadal $s_{n t}$ that matches the evolution of capital from $t$ to $t+1$, given real income and the country-time specific depreciation rate. This approach, together with the fact that our calibration procedure matched perfectly the relative real per capita incomes for each country, ensures that the model matches the observed capital stock from period to period.

The computation of relative costs of the input bundle requires information on wages and the returns to capital. To compute $w_{n t}$, we take the gross non-PPP adjusted labor income in PWT8.0, and divide it by the effective endowment of labor, namely the product of the total employment and the per capita human capital. This yields the payment to one efficiency unit of labor in each country and decade.

Obtaining information on the return to capital, $r_{n t}$, is less straightforward, since it is not observable directly. In the baseline analysis, we impute $r_{n t}$ from the information on the total income, endowment of capital, and the labor share: $r_{n t}=\left(1-\alpha_{n t}\right) Y_{n t} / K_{n t}$, where the labor share $\alpha_{n t}$, total income $Y_{n t}$, and total capital $K_{n t}$ come directly from the PWT8.0. Since the return to capital is notoriously difficult to measure, Section 4.4 evaluates the robustness of the estimates to four alternative ways of inferring $r_{n t}$.

The price of nontradeables relative to the U.S., $p_{n t}^{J+1} / p_{u s t}^{J+1}$, are computed using the detailed

\footnotetext{
${ }^{8}$ The U.S. I-O matrix provides an alternative way of computing $\alpha_{j}$ and $\beta_{j}$. These parameters calculated based on the U.S. I-O table are very similar to those obtained from UNIDO, with the correlation coefficients between them above 0.85 in each case. The U.S. I-O table implies greater variability in $\alpha_{j}$ 's and $\beta_{j}$ 's across sectors than does UNIDO.
} 
price data collected by the International Comparison of Prices Program (ICP). For a few countries and decades, these relative prices are extrapolated using a simple linear fit to log PPP-adjusted per capita GDP from the Penn World Tables.

In order to estimate the relative TFP's in the tradeable sectors in the U.S., we use the 2009 version of the NBER-CES Manufacturing Industry Database, which reports the total output, total input usage, employment, and capital stock, along with deflators for each of these in each sector. The data are available in the 6-digit NAICS classification for the period 1958 to 2005, and are converted into ISIC 2-digit sectors using a concordance developed by the authors. The procedure yields sectoral measured TFP's for the U.S. in each tradeable sector $j=1, \ldots, J$ and each decade.

The share of expenditure on traded goods, $\xi_{n t}$ in each country and decade is sourced from Uy, Yi and Zhang (2013), who compile this information for 30 developed and developing countries. For countries unavailable in the Uy, Yi and Zhang data, values of $\xi_{n t}$ are imputed based on fitting a simple linear relationship to log PPP-adjusted per capita GDP from the Penn World Tables. In each decade, the fit of this simple bivariate regression is typically quite good, with $\mathrm{R}^{2}$ 's of 0.30 to 0.80 across decades.

The baseline analysis assumes that the dispersion parameter $\theta$ does not vary across sectors and sets $\theta=8.28$, which is the preferred estimate of EK. Section 4.4 shows that the productivity estimates are quite similar under two alternative sets of assumptions on $\theta$ : (i) a lower value of $\theta=4$, and (ii) sector-specific values of $\theta_{j}$.

We choose the elasticity of substitution between broad sectors within the tradeable bundle, $\eta$, to be equal to 2 . Since these are very large product categories, it is sensible that this elasticity would be relatively low. It is higher, however, than the elasticity of substitution between tradeable and nontradeable goods, which is set to 1 by the Cobb-Douglas assumption. The elasticity of substitution between varieties within each tradeable sector, $\varepsilon$, is set to 4 (as is well known, in the EK model this elasticity plays no role, entering only the constant $\Gamma$ ).

Appendix Table A1 lists the countries used in the analysis along with the time periods for which data are available for each country, and Appendix Table A2 lists the sectors along with the key parameter values for each sector: $\alpha_{j}, \beta_{j}$, the share of nontradeable inputs in total inputs $\gamma_{J+1, j}$, and the taste parameter $\omega_{j}$. All of the variables that vary over time are averaged for each decade, from the 1960s to the 2000s, and these decennial averages are used in the analysis throughout. Thus, our unit of time is a decade. 


\section{Evolution of Comparative Advantage}

This section describes the basic patterns in how estimated sector-level technology varies across countries and over time, focusing especially on whether comparative advantage has become stronger or weaker. Going through the steps described in Section 3.1 yields, for each country $n$, tradeable sector $j$, and decade $t$, the state of technology relative to the U.S., $T_{n t}^{j} / T_{u s t}^{j}$. Since mean productivity in each sector is equal to $\left(T_{n t}^{j}\right)^{1 / \theta}$, we carry out the analysis on this exponentiated value, rather than $T_{n t}^{j}$.

\subsection{Basic Patterns}

Table 1 presents summary statistics for the OECD and non-OECD countries in each decade. The first column reports the mean productivity relative to the U.S. across all sectors in a country, a measure that can be thought of as absolute advantage. The OECD countries as a group catch up to the U.S. between the 1960s and the 2000s, with productivities going up from 0.91 to in excess of 1 over the period. The non-OECD countries' productivity is lower throughout, but the catch-up is also evident. The second column in each panel summarizes the magnitude of within-country differences in productivity across sectors, i.e., the coefficient of variation of sectoral productivities within a country, averaged by country group and decade. This measure can be thought of as comparative advantage across sectors. The average coefficient of variation is about $50 \%$ lower in the OECD countries compared to the non-OECD, reflecting higher dispersion of sectoral productivities in poorer countries, or "stronger comparative advantage." In both country groups, there is a clear downward trend in the coefficient of variation, which is first evidence that comparative advantage is getting weaker over time - sectoral relative productivity dispersion within a country is falling.

The bottom panel presents the same statistics but balancing the country sample across decades. There are virtually no changes for the OECD, since the OECD sample is more or less balanced to begin with. For the non-OECD, balancing the sample implies dropping 19 countries in later decades, but the basic patterns are unchanged.

The evolution of these averages over time masks a great deal of heterogeneity among countries. To visualize this heterogeneity, Figures $1(\mathrm{a})$ and $1(\mathrm{~b})$ plot the changes in the average $T^{1 / \theta}$ against their initial average values. The left panel does this from the 1960s to the 2000s, the right panel from the 1990s. These plots can be thought of as capturing the traditional (cross-country) notion of absolute convergence. There is quite a bit of dispersion in the extent to which countries caught up on average to U.S. productivity, including a few countries that fell behind on average relative to the U.S.. There is an apparent negative relationship between the extent of catch-up and the initial average level, stronger from the 1990s. 
Figures 1(c) and 1(d) plot the within-country dispersions of productivities (the coefficients of variation) in the 2000s against their values in the 1960 s and the 1990 s, respectively. For convenience, 45-degree lines are added to these plots. There is a fair amount of cross-country variation in productivity dispersion, and this variation appears to be persistent over time. Since the 1960s, sectoral productivity dispersion fell in the majority of countries (in all but 13). Between the 1990s and the 2000s, there is no systematic fall in dispersion: Table 1 shows that the coefficient of variation actually rises on average between those two decades in both groups of countries.

\subsection{Relative Convergence}

To shed further light on whether comparative advantage has gotten stronger or weaker over time, we estimate a convergence specification in the spirit of Barro (1991) and Barro and Sala-i-Martin (1992):

$$
\Delta \log \left(T_{n}^{j}\right)^{1 / \theta}=\beta \text { Initial } \log \left(T_{n}^{j}\right)^{1 / \theta}+\delta_{n}+\delta_{j}+\epsilon_{n j}
$$

Unlike the classic cross-country convergence regression, our specification pools countries and sectors. On the left-hand side is the log change in the productivity of sector $j$ in country $n$. The right-hand side regressor of interest is its beginning-of-period value. All of the specifications include country and sector fixed effects, which affects the interpretation of the coefficient. The country effect absorbs the average change in productivity across all sectors in each country - the absolute advantage. Thus, $\beta$ picks up the impact of the initial relative productivity on the relative growth of a sector within a country - the evolution of comparative advantage. In particular, a negative value of $\beta$ implies that relative to the country-specific average, the most backward sectors grew fastest.

Table 2 presents the results. The first column reports the coefficients for the longest differences: the 1960 s to the 2000s, while the second column estimates the specification starting in the 1980s. The following 4 columns carry out the estimation decade-by-decade, 1960s to 1970s, 1970s to 1980s, and so on. Since the length of the time period differs across columns, the coefficients are not directly comparable. To help interpret the coefficients, underneath each one we report the speed of convergence, calculated according to the standard Barro and Sala-i-Martin (1992) formula: $\beta=e^{-\lambda \mathcal{T}}-1$, where $\beta$ is the regression coefficient on the initial value of productivity, $\mathcal{T}$ is the number of decades between the initial and final period, and $\lambda$ is the convergence speed. This number gives how much of the initial difference between productivities is expected to disappear in a decade. All of the standard errors are clustered by country, to account for unspecified heteroscedasticity at the country level. All of the results are robust to clustering instead at the sector level, and we do not report those standard errors to conserve space. ${ }^{9}$

\footnotetext{
${ }^{9}$ If the initial $T$ 's tend to be measured with error, it has been noted that the convergence regression of the
} 
Column 1 of the top panel reports the estimates for the long-run convergence in the pooled sample of all countries. The coefficient is negative, implying that there is convergence: within a country, the weakest sectors tend to grow faster. It is highly statistically significant: even with clustered standard errors the $t$-statistic is nearly 12. The speed of convergence implied by this coefficient is $18 \%$ per decade. As a benchmark, the classic Barro and Sala-i-Martin (1992) rate of convergence is $2 \%$ per year, or $22 \%$ per decade, close to what we find in a very different setting. The second column estimates the long-difference specification from the 1980s to the 2000s. Once again, the coefficient is negative and highly significant, but it implies a considerably slower rate of convergence, $11.7 \%$ per decade. The rest of the columns report the results decade-by-decade. Though there is statistically significant convergence in each decade, the speed of convergence trends downward, from $26 \%$ from the 1960 to the 1970 s, to $11.4 \%$ in the most recent period.

In order to assess how the results differ across country groups, Panels B and C report the results for the OECD and the non-OECD subsamples separately. Breaking it down produces slightly faster convergence rates than in the full sample. In the decade-to-decade specifications, the non-OECD countries are catching up somewhat faster, which is not surprising.

Figures 2 and 3 present the results graphically. Figure 2 plots the unconditional bivariate relationship between the log change in productivity and the log initial level in each sector. Within most sectors, the negative relationship is evident. In every sector, the estimated coefficient is negative, and in 14 of the 19 sectors, it is significant at the $5 \%$ level. Figure 3 plots the partial correlation between the initial level and subsequent growth, after netting out country and sector fixed effects. This is the partial correlation plot underlying the first coefficient reported in Table 2. Once again, the negative relationship is evident in the pooled sample.

Appendix Tables A3 reports the results of estimating the convergence equation (10) country by country from the 1960 s to today. These results should be treated with more caution, as the sample size is at most 19. The columns report the coefficient, the standard error, the number of observations, the $\mathrm{R}^{2}$, as well as the implied speed of convergence for each country. There is considerable evidence of convergence in these country-specific estimates. In all countries, the

type estimated here will produce bias in favor of finding convergence (Quah 1993). We ran a number of checks to assess the relevance of this effect in our setting. First, we estimated a number of panel specifications with a variety of interacted fixed effects: country $\times$ sector, country $\times$ decade, and sector $\times$ decade included together in estimation. These additional fixed effects will help control for measurement error that varies mainly at country-sector, countrytime, or sector-time level, respectively. We also implemented the Arellano-Bond and Blundell-Bond dynamic panel estimators, that difference the data and use lagged values of $T$ to instrument for current changes in $T$. All of these alternative estimates actually imply a faster speed of convergence than the estimates in Table 2. Second, to check how much measurement error is needed to generate our results, we ran a simulation in which we started with artificial data exhibiting zero convergence across sectors within a country, and added measurement error to the right-hand side variable until the OLS coefficient was equal to the coefficient found in our estimates. It turns out that in order for measurement error to produce coefficient magnitudes found in the data when the truth is zero convergence, it must be the case that $62 \%$ of the cross-sectoral variation in the right-hand side variable is due to measurement error. 
convergence coefficient is negative, and significant at the $10 \%$ level or below in 38 out of 50 available countries $(76 \%)$.

All in all, these results provide robust evidence of relative convergence: in all time periods and broad sets of countries we consider, relatively weak sectors grow faster, with sensible rates of convergence. This implies that Ricardian comparative advantage is getting weaker, at least when measured at the level of broad manufacturing sectors.

\subsection{Discussion}

A large literature in growth, synthesized by Acemoglu (2008, Ch. 18), studies aggregate countrylevel technology differences using multi-country models of technology adoption. This literature has pursued two broad directions. The first postulates that aggregate productivity differences persist because there are frictions in technology adoption. In order to ensure a stable world income distribution, a central assumption in this type of framework is that countries farther behind the world productivity frontier find it easier to increase productivity. This hypothesis dates back to Gerschenkron (1962), and is typically introduced as a reduced-form relationship in these models. The second approach postulates that all technologies are freely available to all countries at all times, but due to capital and/or skill endowment or institutional differences, poorer countries cannot make the best use of the available technologies (Atkinson and Stiglitz 1969, Basu and Weil 1998, Acemoglu and Zilibotti 2001, Caselli and Coleman 2006, Acemoglu, Antrás and Helpman 2007).

Since these models are framed in terms of aggregate technology differences, they are challenging to evaluate empirically. This is because at the country level, it is difficult to distinguish between the role of distance to the world frontier and other country-specific factors, especially when these factors themselves condition the speed of productivity convergence. By opening up a sectoral dimension, our results can provide some empirical evidence on these theories. Our convergence regressions include country fixed effects, and thus control for country-specific determinants of productivity growth affecting all the sectors equally. Though our convergence coefficients capture the notion of within-country convergence, they nonetheless lend support to the key assumption in models of slow technology diffusion: it is easier to catch up starting from a more backward position.

The second approach rationalizes persistent technology gaps by appealing to the appropriateness of world frontier technologies for local country conditions, such as the capital-labor ratio (Atkinson and Stiglitz 1969, Basu and Weil 1998), skill endowment (Acemoglu and Zilibotti 2001, Caselli and Coleman 2006), or institutional quality (Acemoglu et al. 2007). While our results are not geared to informing or testing these theories, we can use the variation in the country-specific 
convergence coefficients in Appendix Table A3 to look for some supporting evidence. Once again, the mapping to existing theories is inexact: our results capture within-country, cross-sectoral speed of convergence, whereas the theoretical literature is about cross-country differences. In addition, variation across sectors in some relevant attributes, such as capital or skill intensity, may play a role as well. Nonetheless, there are some modest but suggestive patterns. The country-specific speed of convergence reported in Appendix Table A3 is positively correlated with the country's capital-labor ratio (correlation 0.54), skill endowment (correlation 0.29), and institutional quality (correlation 0.47$).{ }^{10}$ Of course, these three country characteristics are highly positively correlated, and thus distinguishing between the alternative theories using our data is impractical. However, the positive correlations are suggestive that country characteristics do matter for the speed of technology adoption in ways predicted by theory.

In contrast to the aggregate productivity literature, theories of the dynamics of sectoral technology and Ricardian comparative advantage are quite scarce. Krugman (1987) and Young (1991) develop learning-by-doing models of comparative advantage. A strong implication of these models is that relative productivity differences increase over time - comparative advantage strengthens. This is because learning is faster in sectors that produce more, and comparative advantage sectors are the ones that produce more. Our results are clearly inconsistent with the main prediction of the learning-by-doing models, at least not at the level of broad sectors. Similarly, Grossman and Helpman (1991, Ch. 8) develop a model with a traditional and a knowledge-based sector, and show that one country's initial advantage in the stock of $R \& D$ leads to an increasingly stronger comparative advantage in the knowledge-based sector. Once again, our findings of pervasive convergence in productivity do not support this type of theoretical prediction.

A theoretical and quantitative framework with endogenous sectoral productivity that can be used for understanding the empirical patterns we identify is yet to be developed, and remains a potentially fruitful direction for future research. One promising possibility is the framework of "defensive innovation" in response to import competition recently developed by Bloom, Romer, Terry and Van Reenen (2012) (see also Bloom, Draca and Van Reenen 2011).

\subsection{Robustness of $T$ Estimates}

This section presents a battery of robustness checks on our productivity estimation procedure. The outcomes are summarized in Appendix Table A4. The table reports the mean productivity $T^{1 / \theta}$ relative to the U.S., its standard deviation across countries and sectors, the correlation with the baseline productivity estimates across countries and sectors, and the convergence coefficient

\footnotetext{
${ }^{10}$ These correlations are computed after dropping the 3 outlier countries with the highest speed of convergence point estimates. Without dropping outliers, the correlations are $0.40,0.31$, and 0.42 , respectively. The institutional quality index is "Rule of Law" sourced from the World Bank's Governance Matters Database.
} 
and standard error from the main regression specification (10), estimated on the alternative sets of productivity estimates. To ease comparison, the top row reports the values for the baseline $T^{1 / \theta}$ estimates.

The first set of checks concerns the specification of the gravity equation (6). To assess whether the estimates are sensitive to the set of distance and gravity variables included in estimation, we repeat the analysis while doubling the set of distance intervals (from 6 to 12), and including standard additional controls for common language and colonial ties, which are absent from the baseline specification. As the row labeled "Additional gravity" reveals, the resulting productivity estimates and convergence results are virtually indistinguishable from the baseline.

Next, we estimate the gravity equation in levels using the Poisson Pseudo Maximum Likelihood approach suggested by Santos Silva and Tenreyro (2006). This has the convenient property of not dropping zero trade observations from the estimation sample. The results are once again very similar to the baseline across the board. ${ }^{11}$

The next robustness check concerns whether the trade cost specification includes an exporter or an importer effect. Waugh (2010) appeals to tradeable prices to argue that the specification with an exporter fixed effect fits the data better. In particular, he documents that in the data, tradeable prices are weakly increasing in income. The model with the exporter fixed effect in $d_{n i t}^{j}$ can match this pattern. However, the model with the importer fixed cost in $d_{n i t}^{j}$ delivers the sharply counterfactual prediction that tradeable prices fall in income. In addition, Waugh (2010) shows that the importer fixed effect specification does less well in other dimensions, such as matching observed income differences between countries.

Though we employ a very different model than Waugh (2010) - most importantly, we have multiple tradeable sectors, an explicit non-tradeable sector, and input linkages between those his argument applies in our setting as well, albeit in a milder form. Just as in Waugh (2010), our baseline model with exporter effects in $d_{n i t}^{j}$ delivers a flat tradeable prices-income relationship,

\footnotetext{
${ }^{11} \mathrm{~A}$ standard feature of the baseline procedure is that the trade shares are logged, so that the zero bilateral import flows are dropped from the estimation sample. Unfortunately, our large-scale model cannot be tractably enriched to explicitly account for zeros in trade while at the same time retaining the structural interpretation linking the fixed effects to underlying productivity. However, we can check the ex-post performance of the estimated model with respect to zeros by solving the full model, and computing within the model the sum of the $\pi_{n i t}^{j}$ 's in the importerexporter-sector observations that are zeros in the actual data. We can then examine whether these observations account for large shares of absorption inside the model. If the resulting numbers are large, then the quantitative model predicts substantial trade flows where in reality they are zero. However, if these numbers are small, the model predicts very small flows where the actual flows are zero, providing a good approximation to the data even though baseline productivities are estimated dropping zero trade. The results of this exercise are reported in Appendix Table A5. The exercise takes the most expansive view of the zeros, by assuming that all trade flows missing in the data are actually zeros as well. Observations for which the data exhibit zero/missing trade flows account for a tiny share of overall absorption in our quantitative model: in each decade, these observations add up to on average less than $0.9 \%$ of the total absorption. Breaking down across sectors and decades, we see that nearly all individual sectors or decades, these shares are small. We conclude from this exercise that in spite of ignoring the zero trade observations in estimation, our quantitative model is quite close to the data when it comes to small/zero trade flows.
} 
matching the data. By contrast, when we re-estimate the model with importer effects in $d_{n i t}^{j}$, it implies a negative relationship between tradeable prices and income.

Nonetheless, we present the results of re-estimating sectoral productivities based on the importer effects in $d_{n i t}^{j}$ assumption. The results, presented in row " $i m_{n t}^{j}$ in $d_{n i t}^{j}$ " reveal that the average productivities implied by this alternative approach are lower ( 0.53 at the mean compared to 0.74 for the baseline). However, the dispersion in those productivities is very similar to the baseline, and the two sets of estimates have a correlation of 0.89. Most importantly, the relative convergence result is clearly evident in these estimates, though the speed of convergence is somewhat slower than in the baseline.

The second set of robustness checks concerns the measurement of the return to capital $r_{n t}$, that enters the unit cost terms $c_{n t}^{j}$, and thus the productivity estimates. The baseline computes $r_{n t}$ using data on $K_{n t}$, the total income $Y_{n t}$, and the (country- and time-specific) labor share. However, the return to capital is notoriously difficult to measure, and thus we perform a battery of robustness checks on $r_{n t}$. First, we use the Caselli and Feyrer (2007) correction for natural wealth. The data for natural wealth are for 1995-2005, and come from the World Bank. Even for this later period, not all countries in our baseline sample are covered. In addition, these data are not available before 1995, which forces us to apply the 1995 values to all preceding decades.

Second, we use a measure of the return to capital computed instead from consumption growth. Namely, we exploit the Euler equation in consumption to back out the rate of return on capital: $1+r_{n t+1}-\delta_{n t}=\frac{U^{\prime}\left(C_{n t+1}\right)}{\rho U^{\prime}\left(C_{n t}\right)}$, with $\rho$ the discount factor. We use Penn World Tables data on consumption and the country-specific depreciation rate $\delta_{n t}$, and the standard functional form/parameter assumptions, namely CRRA utility $U(C)=\frac{C^{1-\sigma}}{1-\sigma}$, with $\sigma=2$ and annual $\rho=0.96$. The results are reported in row labeled "Euler."

Third, we use data on lending interest rates from the World Development Indicators. This approach yields a $20 \%$ smaller sample of countries and decades. The results are in the row labeled "Direct." And finally, we adopt the simple assumption that $r_{n t}$ is the same everywhere in the world at a point in time $\left(r_{n t}=r_{u s t} \forall n, t\right)$. This assumption can correspond to financial integration, for instance. Caselli and Feyrer (2007) show that at least as of the 1990s, this is not a bad assumption. The results are in the row "Fin. Integration."

The means and standard deviations of estimated productivities under these four alternative approaches do not differ much from the baseline. The correlations to the baseline are also quite high, from 0.91 under the direct measurement to 0.99 under the Caselli-Feyrer correction. The convergence results are also equally strong under these alternative approaches of measuring $r_{n t}$.

Next, we check the sensitivity of the results to the assumption that the production functions (IO matrices and factor shares) are the same across countries. The row "Country-Specific IO" presents the results of estimating productivities using country-specific IO matrices sourced from 
GTAP. GTAP's coverage of sectors and countries is not the same as in our analysis, requiring some imputation, and thus we do not use these in the baseline analysis. The row "Country-Specific IO, $\alpha, \beta$ " in addition assumes that the labor share in value added $(\alpha)$ and the share of value added in output $(\beta)$ are vary by country and decade (and of course, as always, by sector). We compute these directly for each sector, country, and decade using UNIDO data on the wage bill, value added, and output. We do not use these values in the baseline analysis, because the UNIDO data do not have complete coverage, requiring some imputation. In addition, it can be noisy, and thus variation in these empirical factor shares across countries and over time may not provide a reliable indication of true differences in factor intensity. These two alternative approaches yield slightly higher average productivities, but the variation is similar to the baseline and the correlations are very high. The convergence results are also equally strong.

The final set of checks is on the $\theta$ parameters. First, one may be concerned about how the results change under lower values of $\theta$. Lower $\theta$ implies greater within-sector heterogeneity in the random productivity draws. Thus, trade flows become less sensitive to the costs of the input bundles $\left(c_{n t}^{j}\right)$, and the gains from intra-sectoral trade become larger relative to the gains from inter-sectoral trade. We repeated the estimation assuming instead a value of $\theta=4$, which has been advocated by Simonovska and Waugh (2014) and is at or near the bottom of the range that has been used in the literature. Overall, the results are remarkably similar. The mean productivities are virtually the same, and there is actually somewhat greater variability in $T_{n t}^{j}$ 's under $\theta=4$. The correlation between estimated $T_{n t}^{j}$ 's under $\theta=4$ and the baseline is above 0.94 . The convergence results are equally strong.

Second, a number of studies have suggested that $\theta$ varies across sectors (see, e.g., Chen and Novy 2011, Caliendo and Parro 2014, Imbs and Méjean 2014). We repeat the estimation allowing $\theta_{j}$ to be sector-specific, with sectoral values of $\theta_{j}$ sourced from Caliendo and Parro (2014). The average productivities are once again quite similar, and have an 0.87 correlation with the baseline. The convergence results are if anything stronger than in the baseline.

Another important question is whether our estimates can be cross-validated using direct estimates of measured TFP. Appendix A estimates measured TFP using data on real output and inputs from the OECD Structural Analysis database. It is the most comprehensive database that contains the information required to estimate measured TFP on a consistent basis across countries and over time. Using both simple correlations and regression estimates with fixed effects, we confirm that our baseline estimates indeed exhibit a close positive association with TFP calculated based on STAN data. 


\subsection{Simple Heuristics: What is Driving the Convergence Finding?}

What kinds of basic patterns in the data are driving these results? Though our estimation procedure is based on a theoretically-founded gravity equation and a variety of data sources, and thus is fully internally consistent with the underlying conceptual framework, it would be reassuring if we could show some simple heuristic relationships in the data that are consistent with weakening comparative advantage. We can build intuition as follows: in a simpler model with 2 tradeable and 1 nontradeable sectors, Uy et al. (2013) show analytically that all else equal, a comparative advantage sector has a smaller share of imports in total domestic absorption $1-\pi_{n n}^{j}$ than a comparative disadvantage sector. As a country's comparative advantage in sector $j$ weakens, the import share rises in that sector. This is intuitive: when a country becomes relatively less productive in a sector, it starts importing more.

Thus, weakening comparative advantage should manifest itself in a negative relationship between the initial period import share and the subsequent change in the import share. Sectors within a country with the lowest initial import share $\left(1-\pi_{n n}^{j}\right)$ should see that import share rise. These are the sectors with the strongest comparative advantage at the beginning of the period. Correspondingly, sectors with the highest initial import share should see their import share drop as they catch up in productivity faster.

Figure 4(a) presents this scatterplot, pooling sectors and countries. The negative relationship is remarkably pronounced: the slope coefficient in the simple bivariate regression is -0.397 with a $t$-statistic of 16.5 and an $\mathrm{R}^{2}$ of $18.4 \%$. Note that a significant share of the observations - those below zero on the y-axis - have seen their import share actually fall between the 1960s and today. These declines in import shares would be highly puzzling over the period during which trade costs fell and global trade volumes rose dramatically. A strengthening of comparative advantage in those sectors provides a plausible explanation: countries are getting relatively better in those industries, and thus they need to import less.

This negative relationship would not necessarily be evidence of relative convergence in the $T$ 's if, for instance, trade costs $d_{n i t}^{j}$ fell disproportionately more in sectors in which countries had higher initial import shares. To check for this possibility, Figure 4(b) plots the change in the average trade costs in sector $j$ and country $n$ against the initial import share - the same x-axis variable as in the previous figure. There is virtually no relationship between initial import share and subsequent changes in import costs: the slope coefficient is essentially zero, and the $\mathrm{R}^{2}$ is correspondingly 0.00 . Thus, it does not appear that systematically larger reductions in $d_{n i t}^{j}$ in the initial comparative disadvantage sectors were primarily responsible for the pattern in Figure 4(a). Note that our estimation procedure is designed precisely to take into account any changes in $d_{\text {nit }}^{j}$ (as well as unit factor costs) by importer-exporter pair and sector that may have occurred 
over this period, isolating the underlying productivity changes.

\section{Quantitative Implications}

This section computes the global impact of changes in comparative advantage documented in the previous section. In order to do this, we solve the full model laid out in Section 2 for a variety of values of technology parameters. The main goal of the exercise is to compare outcomes in the world as we see it today to a counterfactual world in which average productivities remain as they are in the data, but relative sectoral productivities are fixed to their initial values. The outcomes we are interested in are trade volumes and patterns, and welfare/real incomes.

Our framework features endogenous capital accumulation. Thus, to model the counterfactual world in which comparative advantage is fixed, we must track what happens to capital in each decade in this case. Our results thus also reflect the impact of changing comparative advantage on capital accumulation over the past 5 decades.

\subsection{Benchmark Results and Model Fit}

The baseline corresponds to the actual values of $T_{n t}^{j}$ estimated for the past five decades. Before running the counterfactual experiments, we assess the fit of the baseline model in a number of dimensions. By construction, the model matches perfectly the real PPP-adjusted per capita income in each country. Table 3 compares $w$ 's and $r$ 's in the model and in the data for 2000s. (The results for the previous decades are similar.) The baseline model performs well: the means and the medians match up fairly well, and the correlation between model and data wages is 0.95. The correlation in $r$ 's is somewhat lower at 0.59 .

The next panel assesses the model's ability to match the sectoral trade flows. It reports the means and medians, across countries and sectors, of $\pi_{n n t}^{j}$. The model reproduces the overall magnitudes well, and the correlation between the model and the data is 0.92 . The same can be said for the cross-border flows $\pi_{n i t}^{j}, i \neq n$, reported in the bottom panel.

\subsection{Counterfactual Comparative Advantage}

In the counterfactual experiments, we solve the model while keeping comparative advantage fixed to the 1960s. Thus, the counterfactual exercise assumes that for each decade $t$ after the 1960s, each country's sectoral productivities relative to the world frontier grew at their geometric average rate, but comparative advantage remained the same as it was in the 1960s. Precisely, the counterfactual 
$\widetilde{T}$ 's are calculated as:

$$
\frac{\widetilde{T}_{n t}^{j}}{T_{F t}^{j}}=\frac{T_{n 1960 s}^{j}}{T_{F 1960 s}^{j}} \times \frac{\left(\prod_{k=1}^{J} \frac{T_{n t}^{k}}{T_{F t}^{k}}\right)^{\frac{1}{J}}}{\left(\prod_{k=1}^{J} \frac{T_{n 1960 s}^{k}}{T_{F 1960 s}^{k}}\right)^{\frac{1}{J}}},
$$

where $T_{F t}^{j}$ is the world frontier in sector $j$ at decade $t$. In each sector and decade, we select the 2 highest values of $T_{n t}^{j} / T_{u s t}^{j}$, take their geometric mean, and label that the global frontier. We then compute each country's technology parameters in the counterfactual with reference to this frontier productivity.

The use of geometric averages has two appealing features. The first is that even though the counterfactual $T$ 's are calculated to keep their distance to the frontier, the geometric average of counterfactual T's is equal to the geometric average of the country's actual $T$ 's at every $t$. This ensures that the normalization to the frontier does not induce movements up or down of the average productivity in the country, which would confound the meaning of our counterfactual exercise. The second appealing feature is that this formulation produces identical counterfactual $T$ 's whether the experiment is carried out on absolute $T$ 's or $T^{1 / \theta}$ 's, which are the mean productivities. We keep productivity in the nontradeable sector at the benchmark value in all the counterfactual experiments, since our focus is on the welfare impact of changes in comparative advantage. Thus, an additional feature of the counterfactual design is that the productivity of tradeables relative to nontradeables is also fixed throughout.

We perform two variants of this counterfactual experiment. The first, labeled "global," keeps relative productivities at their 1960s values for all countries in the world simultaneously. This counterfactual is best suited for evaluating the worldwide consequences of the observed global productivity convergence. The second, "single-country," keeps relative productivities at their initial values for one country at a time, while the rest of the world has their baseline estimated productivities. This counterfactual is ideal for evaluating the consequences for each country of changes in its own comparative advantage.

Countries that join the sample later than the 1960s in the counterfactuals keep their relative productivities fixed to the first decade they are in the data. We think of those initial productivities as our best guess for their pattern of comparative advantage as of the 1960s.

\subsection{Trade Volumes and Trade Patterns}

We begin with the discussion of the impact of changing comparative advantage on observable outcomes, namely international trade volumes and patterns. Table 4 presents the results. The first column reports the value of each moment in the data, the second in the benchmark model, and the third and fourth in the global and single-country counterfactuals, respectively. The numbers 
in italics under the averages are the correlations across countries in each moment between the model and the data.

The first row assesses the impact of changes in comparative advantage on trade volumes. It reports the average manufacturing imports/GDP ratio in the 2000s across the countries in the sample. The mean in the benchmark model matches that in the data almost perfectly, and the correlation between the two is also high at nearly 0.6. The next two columns report the manufacturing import/GDP ratio for the two counterfactuals. It is clear that in the absence of changes in relative productivities, world trade volumes would be even higher than they are today. The difference is sizable: imports to GDP would be 3.7 percentage points higher if all countries kept their initial relative productivities, a $15 \%$ difference.

Next, we look at trade patterns rather than trade volumes, and examine whether the model can match the long-run changes observed in the data. One sharp pattern in the data is that within a sector, export volumes are becoming more similar across countries over time. This is captured in the table by the change in the standard deviation of log shares of world exports within a particular sector across countries. The first column shows that in the data it has decreased systematically between the 1960s and today. While the table reports the cross-sectoral average, this pattern is also pervasive: in 17 out of 19 sectors, the dispersion of log country shares of world exports has fallen. The next column reports the same statistic in the benchmark model, as well as the correlation across sectors between the model and the data. The model matches quite well both the overall decrease, and the cross-sectoral pattern in changes in dispersion. This is not surprising, since the benchmark model parameters are estimated on observed trade flows in each decade, but nonetheless reassuring.

The next column reports the same statistic in the global counterfactual. It is clear that productivity changes are largely responsible for this pattern: when comparative advantage is held fixed, the cross-country dispersion in world export shares is predicted to fall by nearly two-thirds less than in the baseline. ${ }^{12}$

Since world export shares are affected by many other factors, namely trade costs, they do not have a clear model interpretation. It could be, for instance, that world export shares are becoming more similar purely due to changes in trade costs. Thus, we next examine the dispersion in the estimated unit cost terms $S_{n t}^{j}$. Since $\left(S_{n t}^{j}\right)^{1 / \theta}=\left(T_{n t}^{j}\right)^{1 / \theta} c_{n t}^{j}$, it represents the average unit cost of producing a sector $j$ variety in country $n$, time $t$. Data $\left(S_{n t}^{j}\right)^{1 / \theta}$ are estimated in Section 3.1. It is clear that in the data, there has also been a fall in the cross-country dispersion of $\left(S_{n t}^{j}\right)^{1 / \theta}$ within a sector. While the table reports the sectoral average, the pattern is also pervasive, with 17 out of

\footnotetext{
${ }^{12}$ As this exercise concerns the global dispersion in sectoral export shares, it is not well-defined in the singlecountry counterfactual. the same applies to the next exercise, and thus in both cases those entries in the table are left blank.
} 
19 sectors exhibiting falls in dispersion. The next column reports the benchmark model outcome, which matches the data quite well. On the other hand, in the counterfactual, the dispersion in $\left(S_{n t}^{j}\right)^{1 / \theta}$ would have decreased somewhat less on average. In addition, while the benchmark matches the cross-sectoral pattern in the changes in the standard deviation of $S_{n t}^{j}$ very well, the counterfactual does much less so.

Finally, we examine the patterns of intra-industry trade. To that end, we construct the change in the Grubel-Lloyd (GL) index for each country and sector, and report the simple average change in the GL index across countries and sectors. ${ }^{13}$ There has been a considerable increase in the extent of intra-industry trade over time, with an average increase in the data of 0.16 (the GL index has a range of 0 to 1 ). The baseline model matches roughly two-thirds of this magnitude. By contrast, the counterfactuals reveal no increase in the GL index had comparative advantage not changed. Indeed, the single-country counterfactual actually predicts a decrease in intra-industry trade across countries and sectors.

To summarize, observed changes in relative sectoral productivities had an appreciable impact on world trade. Had comparative advantage not changed as it did in the data, trade volumes would be even higher than they are today. In addition, the weakening of comparative advantage accounts well for the increased similarity in export flows between 1960s and today, and for the observed increase in intra-industry trade.

\subsection{Welfare}

Finally, we evaluate the welfare impact of this phenomenon. Our measure of welfare is real per capita income:

$$
\frac{w_{n t}+r_{n t} k_{n t}}{P_{n t}}
$$

where $k_{n t}=K_{n t} / L_{n t}$ is capital per worker. We compare this measure of welfare in the baseline for the 2000s to welfare for the same decade in the counterfactuals. Our model solution assumes that the world is in steady state from the 2000s onwards, and thus analyzing the present discounted value of utility in the 2000s is equivalent to focusing on the period utility in the 2000s.

Table 5 summarizes the results, separating the OECD and the non-OECD countries. The table reports the percentage changes in welfare for the counterfactual relative to the benchmark. Thus, the positive median values in the first column indicate that on average, welfare would have been higher had comparative advantage not changed since the 1960s. This accords well with what is predicted by theory, given the pronounced weakening of comparative advantage we found in the data in Section 4. However, now we can quantify these effects: for the median OECD country,

\footnotetext{
${ }^{13}$ The results are unchanged if instead we used trade-weighed averages, or first computed averages by country, or by sector.
} 
welfare would have been $1.26 \%$ higher had its comparative advantage not weakened. For the non-OECD, the impact would be somewhat larger, $1.80 \%$ at the median. ${ }^{14}$

The second notable aspect of the results is the large dispersion. Among the OECD countries, the standard deviation of welfare changes is $1.34 \%$, while for the non-OECD, it is 3 times higher, $6.62 \%$. Correspondingly, the range of changes is from $-1.14 \%$ to $4.27 \%$ in the OECD, and from $-4.60 \%$ to $41.93 \%$ in the non-OECD. Importantly, among the non-OECD countries, welfare changes range from substantially negative to substantially positive, indicating that heterogeneity across countries is first-order.

The second panel of Table 5 presents the results from the single-country counterfactual. Here, the impact is larger compared to the global counterfactual, at $2.16 \%$ for the OECD and $2.86 \%$ for the non-OECD at the median. The dispersion is slightly higher, and it is more likely that a country is strictly better off keeping its original comparative advantage in the single-country compared to the global counterfactual. The welfare impacts of the two counterfactuals are very similar, with a correlation of $97 \%$.

To cross-check these results and compare magnitudes, the bottom panel of Table 5 reports the same summary statistics for the overall gains from trade compared to autarky for the 2000s in the baseline model. The welfare impact of the evolution of comparative advantage is on average of the same order of magnitude as the total gains from trade. The median gains from trade are $5.64 \%$ for the median OECD country, and $7.22 \%$ for the median non-OECD country. We can also compare the extent of variation in the welfare impact of technological changes to that in the welfare gains from trade. In the OECD, the gains from trade have a standard deviation of about $3.27 \%$ and a range of about $12 \%$ : from a minimum of 1.5 to a maximum of $13.09 \%$. Thus, for the OECD countries the variation in welfare changes due to technology is somewhat smaller, with a range of about 5 percentage points. However, for the non-OECD countries, technology changes have a similar dispersion of welfare impact as trade opening. The gains from trade have a standard deviation of $6.79 \%$, and a range of about $33 \%$. The welfare impact of technology changes has a standard deviation of $6.62 \%$, and a range of nearly 50 percentage points. In addition, while gains from trade are - of course - always positive, the welfare impact of technological changes takes on both positive and negative values.

From the perspective of the trade literature, the preceding welfare assessment is non-standard in one respect. The standard practice in international trade is to keep the factor supply inelastic and fixed. Our model, however, features endogenous capital accumulation. Thus, as comparative advantage remains fixed from the 1960s to today, each country has different income in each decade

\footnotetext{
${ }^{14} \mathrm{~A}$ related but distinct question is what is the population-weighted average welfare change, since averaging with population weights in effect assigns equal weights to individuals, rather than countries. It turns out that the population-weighted welfare change in the counterfactual relative to benchmark is about $0.72 \%$ for the OECD and $2.24 \%$ for the non-OECD.
} 
in the counterfactual compared to the baseline. While the baseline analysis - by construction matches perfectly the evolution of the capital stock in each country and decade, the counterfactual capital stocks will differ from their observed values. If a country that keeps its comparative advantage fixed has higher income in each decade and accumulates more capital, that will have an independent effect on welfare in addition to the static impact of relative productivity. Similarly, to compute the gains from trade relative to autarky, the analysis above assumes that each country is in autarky in each decade starting in the 1960s. Lower income in each decade implies lower capital stock in the future decades, and that will impact the welfare at the end of the period.

To check the importance of this mechanism, we repeat the welfare counterfactuals, but this time assuming that capital is the same as in the baseline. This corresponds to the traditional thought experiment in the trade literature. The results are reported in the bottom panel of Table 5. Without endogenous adjustment of capital, the welfare impact of changes in comparative advantage is smaller throughout. Now, the OECD welfare is only $0.8 \%$ higher in the global counterfactual compared to the baseline, and the non-OECD welfare is $0.5 \%$ higher. The welfare impact is similarly closer to zero in the single-country counterfactual.

As a side note, it is interesting to compare the gains from trade figures. The gains from trade to the OECD are now $3.95 \%$ at the median, or $30 \%$ lower than with capital adjustment. The non-OECD median gains are $23 \%$ lower. Thus, as frequently suggested, trade opening can have a dynamic impact on factor accumulation that will add to the gains from trade. In our case, the dynamic impact is on the accumulation of capital.

\section{Conclusion}

How does technology evolve over time, and what are the consequences of technological change? In the growth literature, it is widely recognized that economic growth is driven in large part by productivity growth, making it the key force for improvements in welfare. However, when relative technology differences are a source of international trade as in the Ricardian world, the welfare impact of technological progress depends on which sectors grow in which countries.

This paper starts by estimating sectoral productivity in a sample of some 72 countries, 19 sectors, and 5 decades, 1960s to today. We document a striking pattern in the data: in the world as a whole, comparative advantage is getting weaker over time. This effect is present in all time periods and major country groups: within a country, sectors with the lowest initial relative productivity experience systematically faster productivity growth than sectors with highest initial productivity. Using counterfactual experiments, we show that had comparative advantage not changed in this way, global trade volumes would be higher, trade shares more dissimilar across countries, and intra-industry trade lower. 
This empirical finding opens the door to the theoretical possibility that this type of uneven technological progress can actually reduce welfare in the trading countries. We indeed find that welfare was reduced by weakening comparative advantage. The average impact is on the same order of magnitude as the total gains from trade for these countries in the 2000s.

The focus of this paper is on measuring how comparative advantage has evolved, and quantifying the impact of this evolution. This exercise leaves open the question of what are the forces driving technological progress and diffusion across countries at the sectoral level. One direction of future research will explore the theoretical mechanisms that could endogenize the patterns uncovered here. The other direction will identify empirically the factors that can account for the evolution of comparative advantage, such as import or export competition, the nature of trading partners, industrial policy, and so on. These two directions are complementary and fruitful avenues for future research. 


\section{Appendix A Comparison of Estimated T's with Measured TFP}

This Appendix compares the productivity estimates obtained by our procedure and used throughout the paper with estimates of measured TFP that can be obtained directly. Computing sectoral measured TFP requires data on total output, employment, capital stocks, and intermediate input usage, all in real terms, by sector. This information is only available at sector level and on a consistent basis for many countries through the OECD Structural Analysis (STAN) database. We first compute sectoral capital stocks using data on real investment and the perpetual inventory method. ${ }^{15}$ We then proceed to compute sector-level measured TFP from data on total output, employment, capital, and inputs following equation (8), for all the countries for which the required data are available. The set of countries and sectors for which this measured TFP can be computed is not large. There are only 12 countries with all the required data in at least some sectors: Austria, Belgium, Czech Republic, Denmark, Finland, France, Greece, Italy, Norway, Slovenia, Sweden, and United States. ${ }^{16}$ The data are in principle available for the period 1970-2008, though in practice earlier years are often not available in individual countries.

It is now well understood that differences in trade openness across sectors will affect measured TFP systematically (see Finicelli et al. 2013, and Section 3.2). To go from measured TFP to true underlying TFP, we apply the Finicelli et al. (2013) correction specified for the U.S. in equation (9) to all countries and sectors.

We then correlate the TFP values estimated based on STAN with the T's from our baseline procedure. We present the comparison for the 2000s, as the latest time period has the largest number of observations, and the measures of capital stocks are also more reliable. Panel A of Table A6 reports, for each sector, the Spearman rank correlation between the two measures. These tend to be high: the mean correlation correlations across sectors is 0.71 , and the median 0.80. The last column reports the number of countries for which STAN-based TFP is available in each sector. We can see that we have have information for less than 10 countries per sector. To make more efficient use of the data, we next pool the sectors and examine the correlation between the two productivity measures in a regression framework:

$$
\log \operatorname{TFP}_{-} \mathrm{STAN}_{n}^{j}=\beta \log \left(T_{n}^{j}\right)^{1 / \theta}+\delta_{n}+\delta_{j}+\epsilon_{n j}
$$

where TFP-STAN $_{n}^{j}$ is the TFP as implied by the STAN data, and $T_{n}^{j}$ is as defined in the rest of the paper. The specification includes both country and sector effects, and thus the average productivity levels in individual countries and sectors are netted out. Panel B of Table A6 reports the results. The first column reports the simple bivariate regression of the two measures. The

\footnotetext{
${ }^{15}$ Though the STAN database contains a variable for sectoral capital stock, it is only available for 6 countries.

${ }^{16}$ In practice, the main bottleneck appears to be data on investment, and therefore capital stocks.
} 
coefficient is highly statistically significant. The correlation between the two variables is 0.37 . The second column adds sector effects. The coefficient remains statistically significant at the $1 \%$ level, and the partial correlation, obtained after netting the sector effects from both measures of productivity, is much higher at 0.583 . Finally, column (3) includes both sector and country effects. The coefficient of interest is significant at the $5 \%$ level. With country and sector fixed effects, the overall $\mathrm{R}^{2}$ is about 0.89 . Given that, it is remarkable that the partial correlation between the two measures, after controlling for both country and sector effects is 0.08 . Thus, even after netting out all the sector and country effects, the association between these two variables is close and statistically significant.

We conclude from these exercises that our estimation procedure that relies on bilateral trade to measure productivity delivers results that are in line with the more conventional approaches. ${ }^{17}$

\section{Appendix B Solution Algorithm}

A model period is one decade. The calibration and estimation yields the following series: (i) country-specific and time-varying series $\left\{L_{n t}, T_{n t}^{j}, \xi_{n t}, \delta_{n t}, s_{n t}, d_{n i t}^{j}\right\}$ for 5 decades; and (ii) timeinvariant parameters common across countries and decades $\left\{\varepsilon, \eta, \theta, \omega_{j}, \alpha_{j}, \beta_{j}, \gamma_{j^{\prime} j}\right\}$. The capital stocks in the initial decade are $K_{n 0}$. We assume that the model economy is in steady state from fifth period (the last period of the data) onward by setting the time-varying series at their fifth decade values for all $t>5$ in each country $n$. We compute the competitive equilibrium of the model for each period as follows:

1. Guess $\left\{w_{n t}, r_{n t}\right\}_{n=1}^{N}$.

- Compute prices from the following equations:

$$
\begin{gathered}
c_{n t}^{j}=\left(w_{n t}^{\alpha_{j}} r_{n t}^{1-\alpha_{j}}\right)^{\beta_{j}}\left(\prod_{j^{\prime}=1}^{J+1}\left(p_{n t}^{j^{\prime}}\right)^{\gamma_{j^{\prime} j}}\right)^{1-\beta_{j}} \text { for all } n \text { and } j, \\
\Phi_{n t}^{j}=\sum_{i=1}^{N} T_{i t}^{j}\left(c_{i t}^{j} d_{n i t}^{j}\right)^{-\theta} \text { for all } n \text { and } j \in\{1, \ldots, J\}, \\
\Phi_{n t}^{J+1}=T_{n t}^{J+1}\left(c_{n t}^{J+1}\right)^{-\theta} \text { for all } n,
\end{gathered}
$$

\footnotetext{
${ }^{17}$ An alternative source of sector-level productivity estimates is the Groningen Growth and Development Centre Productivity Level Database (http://www.ggdc.net/databases/levels.htm). These data are available only at a single point in time, 1997. The database reports levels of multifactor productivity relative to the U.S. for 12 manufacturing sectors and 19 developed countries. We repeated the analysis above using the Groningen data instead. Though the sector-level correlations were somewhat lower than what is reported for STAN, the coefficients from the fixed effects regression were more significant, and the Partial $\mathrm{R}^{2}$ comparable to that for STAN.
} 


$$
\begin{gathered}
p_{n t}^{j}=\Gamma\left(\Phi_{n t}^{j}\right)^{-\frac{1}{\theta}} \text { for all } n \text { and } j \\
P_{n t}=B_{n}\left(\sum_{j=1}^{J} \omega_{j}\left(p_{n t}^{j}\right)^{1-\eta}\right)^{\frac{1}{1-\eta} \xi_{n t}}\left(p_{n t}^{J+1}\right)^{1-\xi_{n t}} \text { for all } n .
\end{gathered}
$$

- Compute final demand as follows: for any country $n$,

$$
\begin{gathered}
Y_{n t}^{j}=\xi_{n t} \frac{w_{n t} L_{n t}+r_{n t} K_{n t}}{p_{n t}^{j}} \frac{\omega_{j}\left(p_{n t}^{j}\right)^{1-\eta}}{\sum_{k=1}^{J} \omega_{k}\left(p_{n t}^{k}\right)^{1-\eta}}, \text { for } j=\{1, . ., J\}, \\
Y_{n t}^{J+1}=\left(1-\xi_{n t}\right) \frac{w_{n t} L_{n t}+r_{n t} K_{n t}}{p_{n t}^{J+1}} .
\end{gathered}
$$

- Compute consumption, investment and next-period capital: for any country $n$,

$$
C_{n t}=\left(1-s_{n t}\right) Y_{n t} ; \quad I_{n t}=s_{n t} Y_{n t} ; \quad K_{n t+1}=\left(1-\delta_{n t}\right) K_{n t}+I_{n t} .
$$

- Compute the trade shares as follows: for any country pair $(n, i)$ and $j \in\{1, \ldots, J\}$

$$
\pi_{n i t}^{j}=\frac{T_{i t}^{j}\left(c_{i t}^{j} d_{n i t}^{j}\right)^{-\theta}}{\Phi_{n t}^{j}}
$$

- Compute total demand as follows: for any country $n$ and any sector $j$

$$
p_{n t}^{j} Y_{n t}^{j}+\sum_{j^{\prime}=1}^{J}\left(\sum_{i=1}^{N} Q_{i t}^{j^{\prime}} p_{i t}^{j^{\prime}} \pi_{i n t}^{j^{\prime}}\right)\left(1-\beta_{j^{\prime}}\right) \gamma_{j j^{\prime}}+Q_{n t}^{J+1} p_{n t}^{J+1}\left(1-\beta_{J+1}\right) \gamma_{j, J+1}=p_{n t}^{j} Q_{n t}^{j} .
$$

- Compute the factor allocations across sectors as follows: for any country $n$,

$$
\begin{gathered}
\sum_{i=1}^{N} p_{i t}^{j} Q_{i t}^{j} \pi_{i n t}^{j}=\frac{w_{n t} L_{n t}^{j}}{\alpha_{j} \beta_{j}}=\frac{r_{n t} K_{n t}^{j}}{\left(1-\alpha_{j}\right) \beta_{j}}, \text { for all } j=\{1, . ., J\}, \\
p_{n t}^{J+1} Q_{n t}^{J+1}=\frac{w_{n t} L_{n t}^{J+1}}{\alpha_{J+1} \beta_{J+1}}=\frac{r_{n t} K_{n t}^{J+1}}{\left(1-\alpha_{J+1}\right) \beta_{J+1}} .
\end{gathered}
$$

2. Update $\left\{w_{n t}^{\prime}, r_{n t}^{\prime}\right\}_{n=1}^{N}$ with the feasibility conditions for factors: for any $n$,

$$
\sum_{j=1}^{J+1} L_{n t}^{j}=L_{n t}, \quad \sum_{j=1}^{J+1} K_{n t}^{j}=K_{n t}
$$

3. Repeat the above procedures until $\left\{w_{n t}^{\prime}, r_{n t}^{\prime}\right\}_{n=1}^{N}$ is close enough to $\left\{w_{n t}, r_{n t}\right\}_{n=1}^{N}$. 


\section{References}

Acemoglu, Daron, Introduction to Modern Economic Growth, Princeton, NJ: Princeton University Press, 2008.

and Fabrizio Zilibotti, "Productivity Differences," Quarterly Journal of Economics, May 2001, 116 (2), 563-606.

, Pol Antrás, and Elhanan Helpman, "Contracts and Technology Adoption," American Economic Review, June 2007, 97 (3), 916-943.

Atkinson, Anthony B. and Joseph E. Stiglitz, "A New View of Technological Change," Economic Journal, Royal Economic Society, September 1969, 79 (315), 573-78.

Barro, Robert J., "Economic Growth in a Cross Section of Countries," Quarterly Journal of Economics, May 1991, 106 (2), 407-443.

and Xavier Sala-i-Martin, "Convergence," Journal of Political Economy, April 1992, 100 (2), 223-251.

Bartelsman, Eric J. and Wayne Gray, "The NBER Manufacturing Productivity Database," October 1996. NBER Technical Working Paper 205.

Basu, Susanto and David N. Weil, "Appropriate Technology And Growth," Quarterly Journal of Economics, November 1998, 113 (4), 1025-1054.

Bernard, Andrew B. and Charles I. Jones, "Technology and Convergence," Economic Journal, July 1996a, 106, 1037-1044.

and __ , "Comparing Apples to Oranges: Productivity Convergence and Measurement Across Industries and Countries," American Economic Review, December 1996b, 86, 12161238.

Berthelon, Matias and Caroline Freund, "On the Conservation of Distance in International Trade," Journal of International Economics, July 2008, 75 (2), 310-320.

Bloom, Nicholas, Mirko Draca, and John Van Reenen, "Trade Induced Technical Change: The Impact of Chinese Imports on Innovation, Diffusion and Productivity," January 2011. NBER WP 16717.

, Paul Romer, Stephen J. Terry, and John Van Reenen, "A Trapped Factors Model of Innovation," July 2012. Mimeo, Stanford University, NYU Stern, and LSE.

Brezis, Elise S., Paul R. Krugman, and Daniel Tsiddon, "Leapfrogging in International Competition: A Theory of Cycles in National Technological Leadership," American Economic Review, December 1993, 83 (5), 1211019.

Caliendo, Lorenzo and Fernando Parro, "Estimates of the Trade and Welfare Effects of NAFTA," May 2014. Forthcoming Review of Economic Studies.

Carrère, Céline, Olivier Cadot, and Vanessa Strauss-Kahn, "Export Diversification: What's behind the Hump?," Review of Economics and Statistics, May 2011, 93 (2), 590-605.

Caselli, Francesco, "Accounting for Cross-Country Income Differences," in Steven Durlauf Philippe Aghion, ed., Handbook of Economic Growth, Vol. 1, Elsevier-North Holland, 2005, chapter 9, pp. 679-741.

and James Feyrer, "The Marginal Product of Capital," Quarterly Journal of Economics, May 2007, 122 (2), 535-568.

and Wilbur John Coleman, "The World Technology Frontier," American Economic Review, June 2006, 96 (3), 499-522. 
Chen, Natalie and Dennis Novy, "Gravity, Trade Integration, and Heterogeneity across Industries," Journal of International Economics, November 2011, 85 (2), 206-221.

Chor, Davin, "Unpacking Sources of Comparative Advantage: A Quantitative Approach," Journal of International Economics, November 2010, 82 (2), 152-167.

Costinot, Arnaud, Dave Donaldson, and Ivana Komunjer, "What Goods Do Countries Trade? A Quantitative Exploration of Ricardo's Ideas," Review of Economic Studies, April 2012, 79 (2), 581-608.

Deardorff, Alan V., "The General Validity of the Law of Comparative Advantage," Journal of Political Economy, October 1980, 88 (5), 941-57.

Do, Quy-Toan and Andrei A. Levchenko, "Comparative Advantage, Demand for External Finance, and Financial Development," Journal of Financial Economics, December 2007, 86 (3).

Eaton, Jonathan and Samuel Kortum, "Technology, Geography, and Trade," Econometrica, September 2002, 70 (5), 1741-1779.

Finicelli, Andrea, Patrizio Pagano, and Massimo Sbracia, "Trade-revealed TFP," October 2009. Bank of Italy Temi di Discussione (Working Paper) No. 729. _ $\underset{96-109 .}{ }$, and _ _ , "Ricardian Selection," Journal of International Economics, 2013, 89 (1),

Gerschenkron, Alexander, Economic backwardness in historical perspective, a book of essays, Cambridge, Mass.: Belknap Press of Harvard University Press, 1962.

Grossman, Gene M. and Elhanan Helpman, Innovation and Growth in the Global Economy, Cambridge, Mass.: MIT Press, 1991.

Hall, Robert and Charles I. Jones, "Why Do Some Countries Produce So Much More Output per Worker then Others," Quarterly Journal of Economics, 1999, 114, 83-116.

Hausmann, Ricardo and Bailey Klinger, "The Structure of the Product Space and the Evolution of Comparative Advantage," April 2007. CID Working Paper No. 146.

Hicks, John, "An Inaugural Lecture," Oxford Economic Papers, 1953, 5 (2), 117-135.

Hsieh, Chang-Tai, "What Explains the Industrial Revolution in East Asia? Evidence From the Factor Markets," American Economic Review, June 2002, 92 (3), 502-526.

and Ralph Ossa, "A global view of productivity growth in China," February 2011. NBER Working Paper No. 16778.

Hummels, David, Jun Ishii, and Kei-Mu Yi, "The Nature and Growth of Vertical Specialization in World Trade," Journal of International Economics, June 2001, 54, 75-96.

Hymans, Saul H. and Frank P. Stafford, "Divergence, Convergence, and the Gains from Trade," Review of International Economics, 1995, 3 (1), 118-123.

Imbs, Jean and Isabelle Méjean, "Elasticity Optimism," April 2014. Forthcoming American Economic Journal: Marcoeconomics.

and Romain Wacziarg, "Stages of Diversification," American Economic Review, March 2003, 93 (1), 63-86.

Jones, Ronald, "Technical Progress and Real Income in a Ricardian Trade Model," in Ronald Jones, ed., Internarional Trade: Essays in Theory, Amsterdam: North-Holland, 1979.

Keller, Wolfgang, "International Technology Diffusion," Journal of Economic Literature, September 2004, 42 (3), 752-782. 
Klenow, Peter J. and Andrés Rodríguez-Clare, "The Neoclassical Revival in Growth Economics: Has It Gone Too Far?," NBER Macroeconomics Annual, 1997, 12, 73-103.

Krugman, Paul, "A Model of Innovation, Technology Transfer, and the World Distribution of Income," Journal of Political Economy, April 1979, 87 (2), 253-66.

_ - "The narrow moving band, the Dutch disease, and the competitive consequences of Mrs. Thatcher: Notes on trade in the presence of dynamic scale economies," Journal of Development Economics, 1987, 27 (1-2), 41-55.

Proudman, James and Stephen Redding, "Evolving Patterns of International Trade," Review of International Economics, 2000, 8 (3), 373-396.

Quah, Danny, "Galton's Fallacy and Tests of the Convergence Hypothesis," Scandinavian Journal of Economics, December 1993, 95 (4), 427-443.

Rodrik, Dani, "Unconditional Convergence in Manufacturing," Quarterly Journal of Economics, 2013, 128 (1), 165-204.

Rose, Andrew K., "Do We Really Know That the WTO Increases Trade?," American Economic Review, March 2004, 94 (1), 98-114.

Samuelson, Paul A., "Where Ricardo and Mill Rebut and Confirm Arguments of Mainstream Economists Supporting Globalization," Journal of Economic Perspectives, 2004, 18 (3), 135146.

Santos Silva, João M.C. and Silvana Tenreyro, "The Log of Gravity," Review of Economics and Statistics, 2006, 88 (4), 641-658.

Shikher, Serge, "Capital, technology, and specialization in the neoclassical model," Journal of International Economics, March 2011, 83 (2), 229-242.

__ , "Putting industries into the Eaton-Kortum model," Journal of International Trade and Economic Development, 2012, 21 (6), 807-837.

Simonovska, Ina and Michael E. Waugh, "The Elasticity of Trade: Estimates and Evidence," Journal of International Economics, January 2014, 92 (1), 34-50.

Solow, Robert M., "A Contribution to the Theory of Economic Growth," Quarterly Journal of Economics, 1956, 70 (1), 65-94.

Swan, Trevor W., "Economic Growth and Capital Accumulation," Economic Record, 1956, 32 (2), 334-361.

Uy, Tim, Kei-Mu Yi, and Jing Zhang, "Structural Change in an Open Economy," Journal of Monetary Economics, September 2013, 60 (6), 667-682.

Waugh, Michael E., "International Trade and Income Differences," American Economic Review, December 2010, 100 (5), 2093-2124.

Young, Alwyn, "Learning by Doing and the Dynamic Effects of International Trade," Quarterly Journal of Economics, May 1991, 106 (2), 369-405. 
Table 1. Summary Statistics

\begin{tabular}{|c|c|c|c|c|c|c|}
\hline & \multicolumn{3}{|c|}{ OECD } & \multicolumn{3}{|c|}{ Non-OECD } \\
\hline & $\begin{array}{c}\text { Mean } \\
T^{1 / \theta}\end{array}$ & $\begin{array}{c}\mathrm{CV} \\
T^{1 / \theta}\end{array}$ & Countries & $\begin{array}{c}\text { Mean } \\
T^{1 / \theta}\end{array}$ & $\begin{array}{c}\mathrm{CV} \\
T^{1 / \theta}\end{array}$ & Countries \\
\hline $1960 \mathrm{~s}$ & 0.911 & 0.128 & 21 & 0.474 & 0.241 & 31 \\
\hline $1970 \mathrm{~s}$ & 1.048 & 0.110 & 21 & 0.571 & 0.216 & 35 \\
\hline $1980 \mathrm{~s}$ & 0.986 & 0.110 & 22 & 0.586 & 0.222 & 39 \\
\hline $1990 \mathrm{~s}$ & 1.041 & 0.103 & 22 & 0.553 & 0.209 & 50 \\
\hline $2000 \mathrm{~s}$ & 1.028 & 0.108 & 22 & 0.585 & 0.212 & 50 \\
\hline Balans & ed Pan & Countr & & & & \\
\hline $1960 \mathrm{~s}$ & 0.911 & 0.128 & 21 & 0.474 & 0.241 & 31 \\
\hline $1970 \mathrm{~s}$ & 1.048 & 0.110 & 21 & 0.591 & 0.214 & 31 \\
\hline $1980 \mathrm{~s}$ & 0.973 & 0.110 & 21 & 0.586 & 0.219 & 31 \\
\hline $1990 \mathrm{~s}$ & 1.031 & 0.102 & 21 & 0.560 & 0.215 & 31 \\
\hline $2000 \mathrm{~s}$ & 1.026 & 0.109 & 21 & 0.553 & 0.224 & 31 \\
\hline
\end{tabular}

Notes: This table reports the summary statistics for the average productivity relative to the US (mean $T^{1 / \theta}$ ), the coefficient of variation among tradeable sector productivities $\left(\mathrm{CV} T^{1 / \theta}\right)$, as well as the number of countries for which data are available. The samples are split by decade and into OECD and non-OECD groups. 


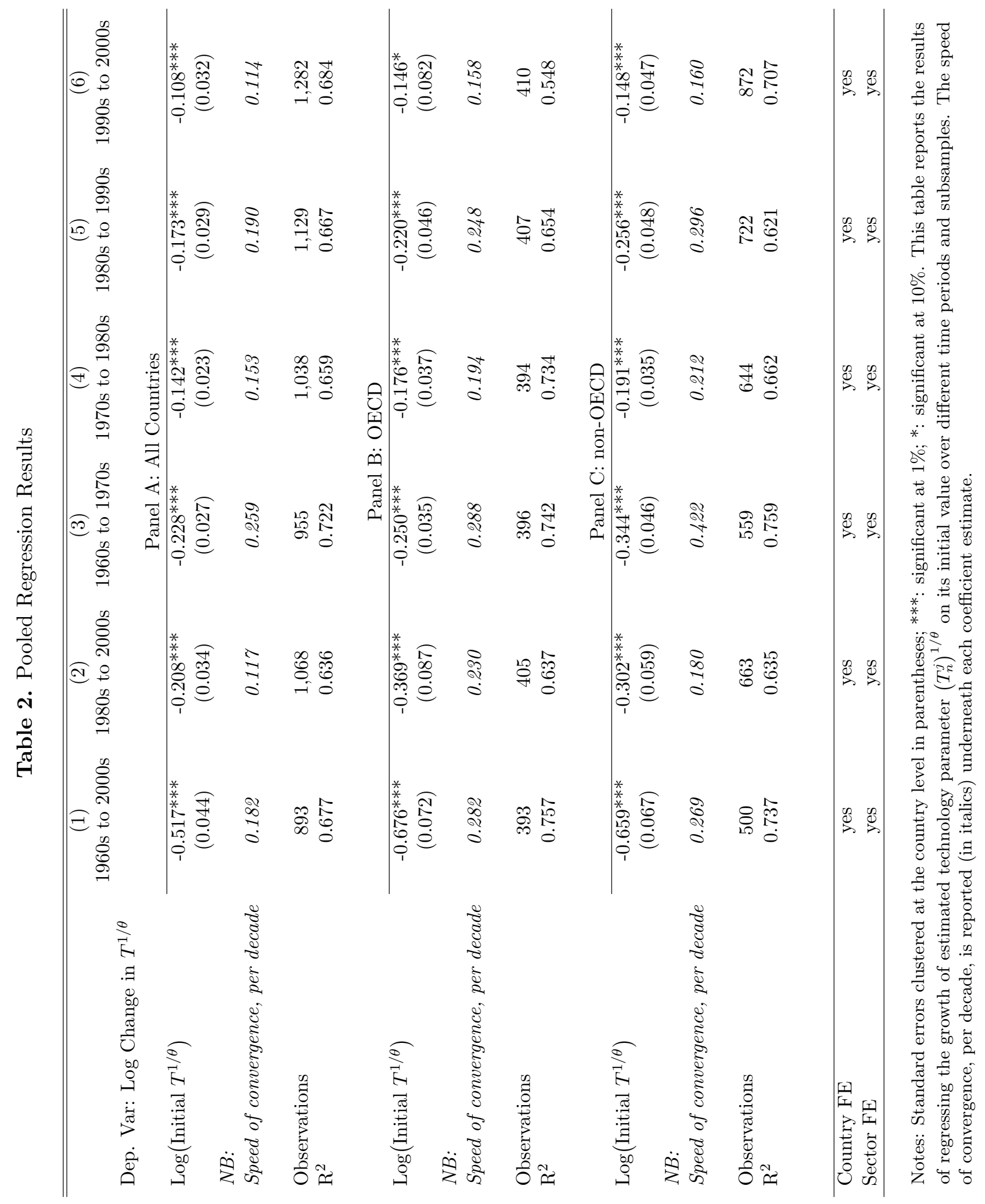


Table 3. The Fit of the Baseline Model with the Data

\begin{tabular}{|c|c|c|c|}
\hline & & model & data \\
\hline \multicolumn{4}{|l|}{ Wages: } \\
\hline & mean & 0.464 & 0.400 \\
\hline & median & 0.277 & 0.172 \\
\hline & corr(model, data) & \multicolumn{2}{|c|}{0.952} \\
\hline \multicolumn{4}{|c|}{ Return to capital: } \\
\hline & mean & 0.173 & 0.172 \\
\hline & median & 0.160 & 0.154 \\
\hline & corr(model, data) & \multicolumn{2}{|c|}{0.588} \\
\hline \multicolumn{4}{|l|}{$\pi_{n n}^{j}:$} \\
\hline & mean & 0.638 & 0.570 \\
\hline & median & 0.710 & 0.614 \\
\hline & corr(model, data) & \multicolumn{2}{|c|}{0.922} \\
\hline \multicolumn{4}{|c|}{$\pi_{n i}^{j}, i \neq j:$} \\
\hline & mean & 0.0051 & 0.0060 \\
\hline & median & 0.0002 & 0.0002 \\
\hline & corr(model, data) & \multicolumn{2}{|c|}{0.904} \\
\hline
\end{tabular}

Notes: This table reports the means and medians of wages relative to the U.S. (top panel); return to capital relative to the U.S. (second panel), share of domestically produced goods in overall spending (third panel), and share of goods from country $i$ in overall spending (bottom panel) in the model and in the data. Wages and return to capital in the data are calculated as described in Section 3.3. 
Table 4. Trade Volumes and Trade Patterns in the Data and in the Model

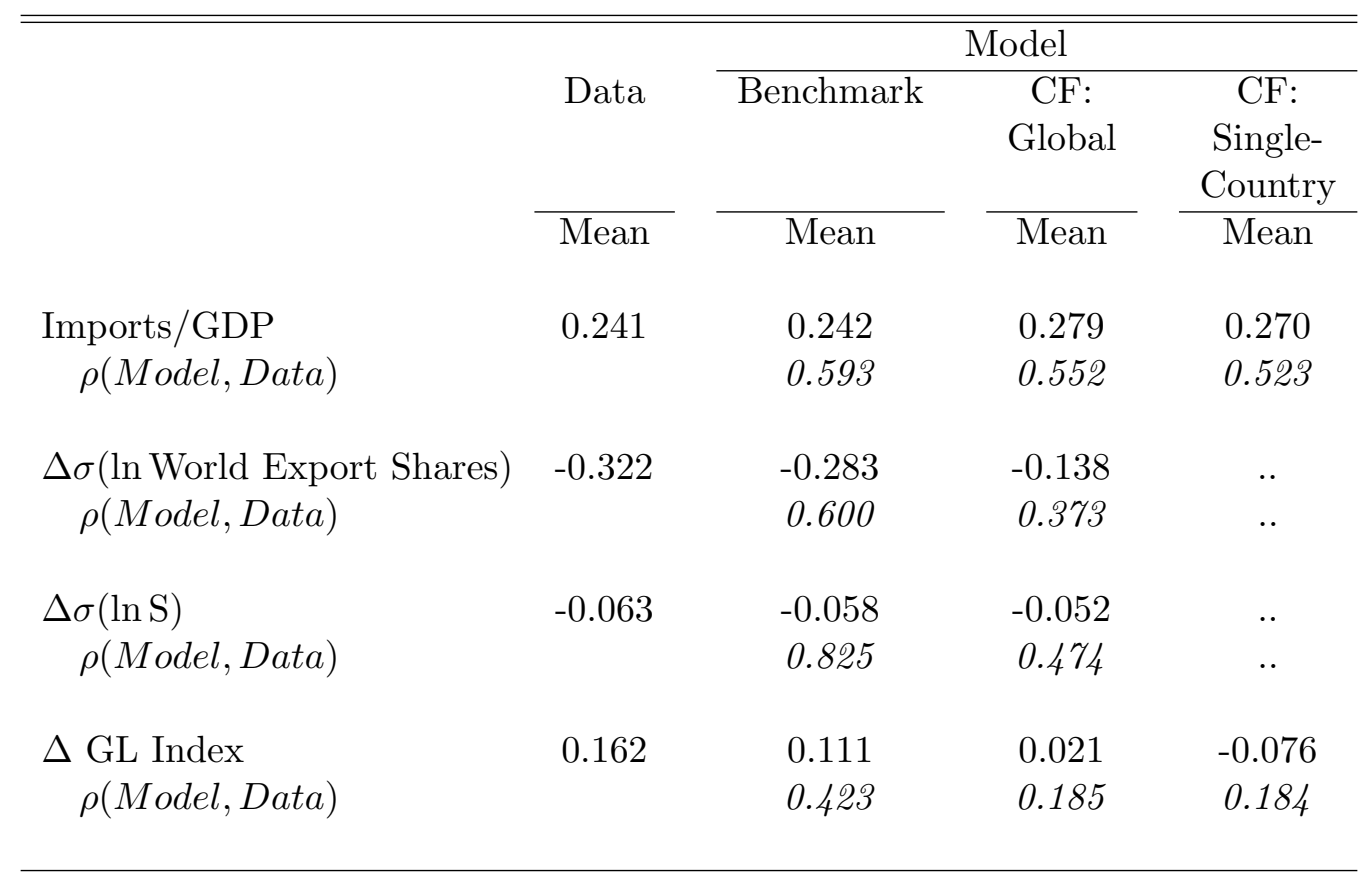

Notes: This table compares the 2000s trade volumes and trade patterns in the data, the benchmark model, and the counterfactuals. The columns labeled "CF" refer to the counterfactuals. The row " $\Delta \sigma$ (ln World Export Shares)" presents the change in the standard deviation of log world export shares between the 1960 s and the 2000 s, averaged across sectors. The row " $\Delta \sigma(\ln S)$ " presents the change in the standard deviation of $\log$ estimated $S_{n t}^{j}$ 's between the $1960 \mathrm{~s}$ and the $2000 \mathrm{~s}$, averaged across sectors. The row " $\Delta$ GL Index" reports the change in the Grubel-Lloyd index, averaged across countries and sectors. 
Table 5. Welfare Gains in the Counterfactuals Relative to Baseline

\begin{tabular}{lccccc}
\hline \hline \multicolumn{7}{c}{ Median } & St. Dev. & Min & Max & Countries \\
Main Results \\
\hline \multicolumn{7}{l}{ Global counterfactual } \\
OECD & 1.26 & 1.34 & -1.14 & 4.27 & 22 \\
Non-OECD & 1.80 & 6.62 & -4.60 & 41.93 & 50 \\
\multicolumn{7}{l}{ Single-country counterfactual } & & & \\
OECD & 2.16 & 1.45 & -0.40 & 5.45 & \\
Non-OECD & 2.68 & 7.51 & -4.93 & 45.84 & \\
NB: Overall gains from trade & & & \\
OECD & 5.64 & 3.27 & 1.50 & 13.09 & \\
Non-OECD & 7.22 & 6.79 & 1.41 & 34.46 & \\
\hline
\end{tabular}

\section{Fixed Capital}

\begin{tabular}{lccccc}
\multicolumn{6}{l}{ Global counterfactual } \\
OECD & 0.80 & 0.92 & -1.03 & 2.80 & 22 \\
Non-OECD & 0.49 & 4.68 & -5.80 & 27.56 & 50 \\
\multicolumn{7}{l}{ Single-country counterfactual } & & & \\
OECD & 1.39 & 1.04 & -0.31 & 3.65 & \\
Non-OECD & 1.77 & 5.34 & -3.68 & 30.50 \\
NB: Overall gains from trade & & & \\
OECD & 3.95 & 2.23 & 1.16 & 8.48 \\
Non-OECD & 5.61 & 4.62 & 1.00 & 23.98 \\
\hline
\end{tabular}

Notes: Units are in percentage points. This table reports the percent change in welfare under the counterfactual scenarios with respect to the baseline. The top panel reports the main results, in which capital accumulation responds endogenously to comparative advantage. The bottom panel reports the results when capital is fixed at its observed values. The counterfactuals labeled "Global counterfactual" assume that all countries' comparative advantage remained fixed to the 1960s values. The counterfactuals labeled "Singlecountry counterfactual" assume for each individual country, comparative advantage remained as it was in the 1960s. All other countries' comparative advantage is taken from the data. In the baseline comparative advantage is as it is in the data for the 2000s. The table also reports the total gains from trade relative to autarky in the baseline for the 2000s. 

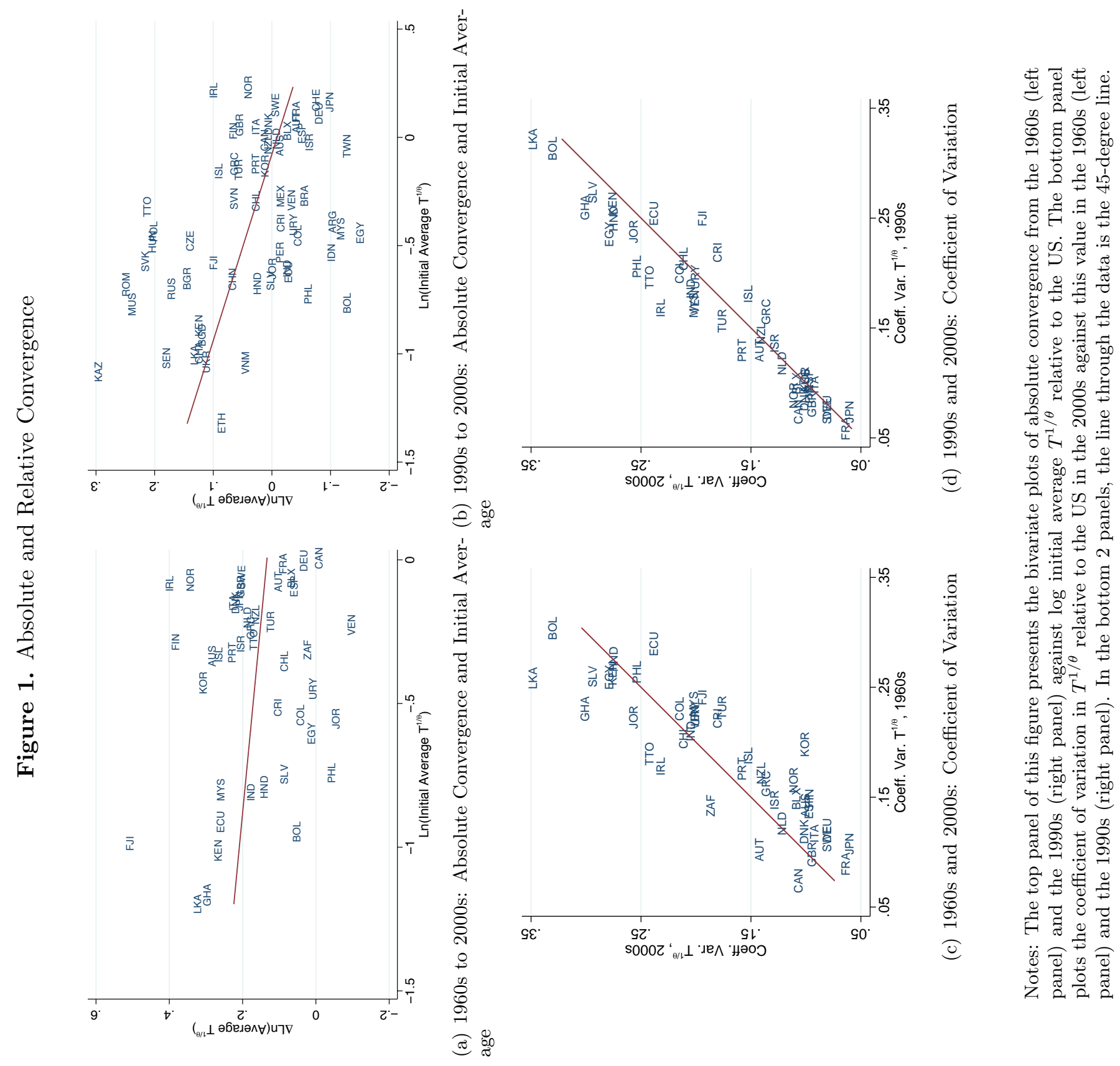


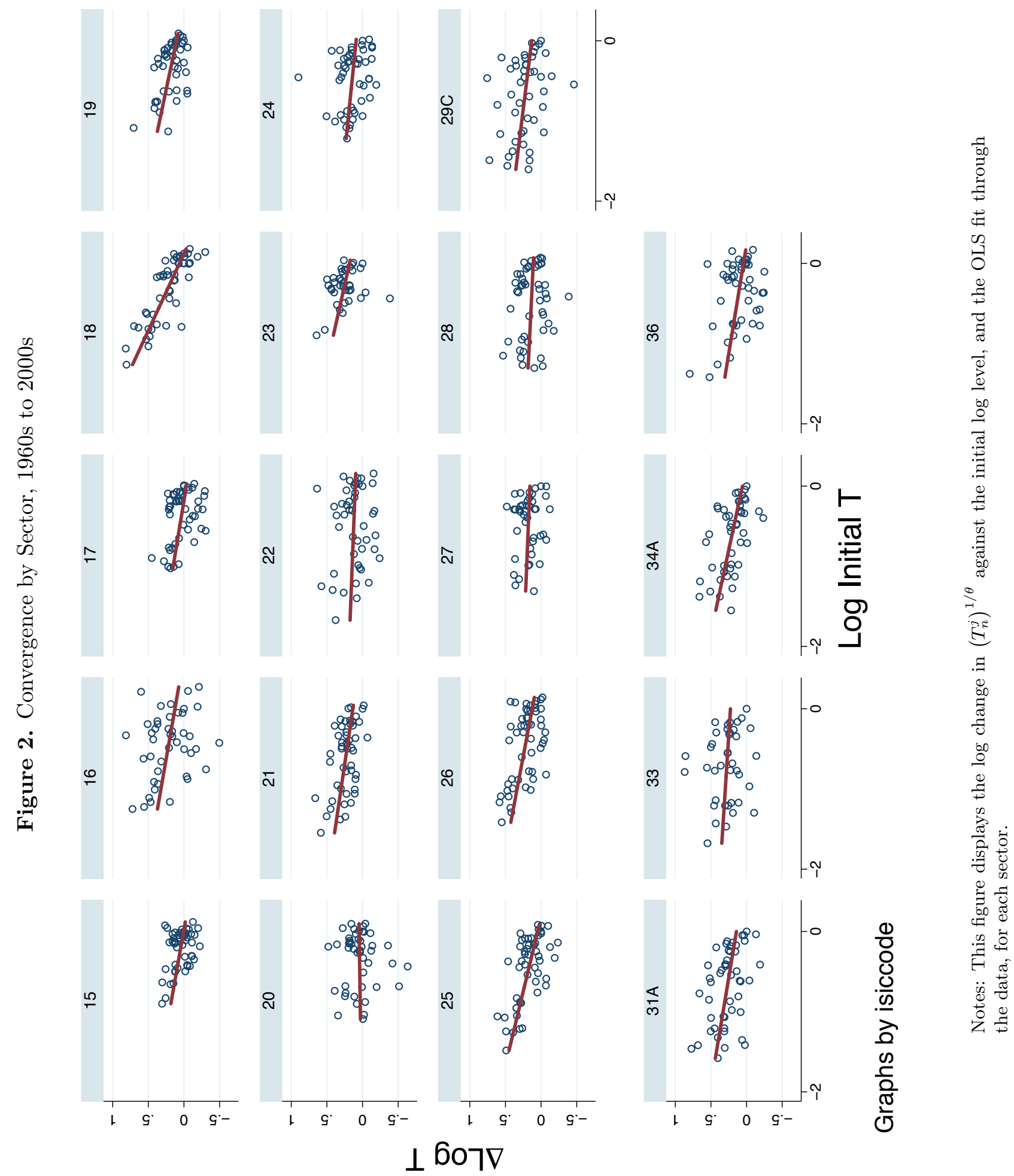


Figure 3. Convergence in the Pooled Sample, 1960s to 2000s

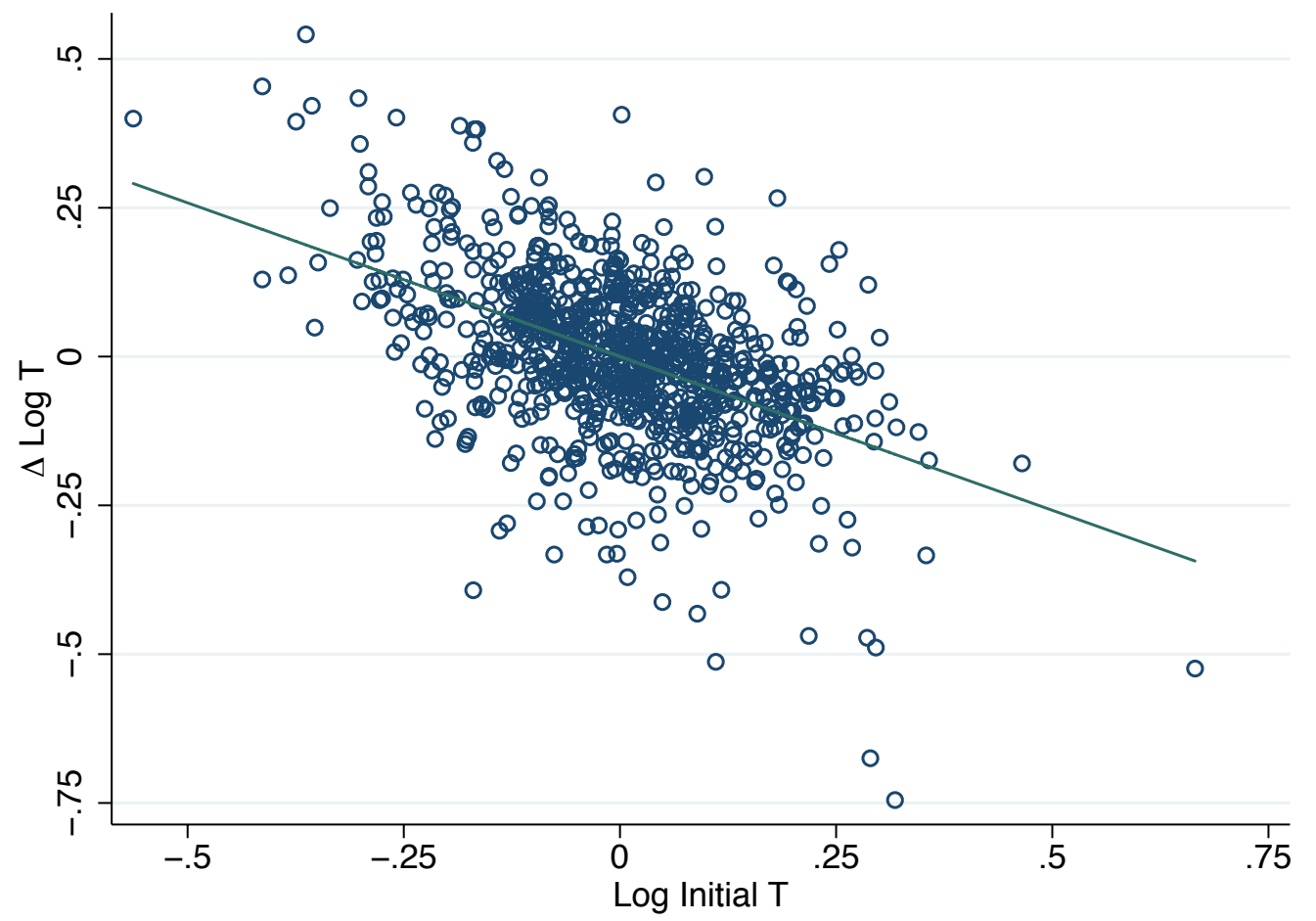

Notes: This figure displays partial correlation the log change in $\left(T_{n}^{j}\right)^{1 / \theta}$ against the initial log level, after netting out country and sector effects, pooling across sectors and countries. 
Figure 4. Heuristic Evidence: Initial Import Shares, Changes in Import Shares, and Changes in Trade Costs

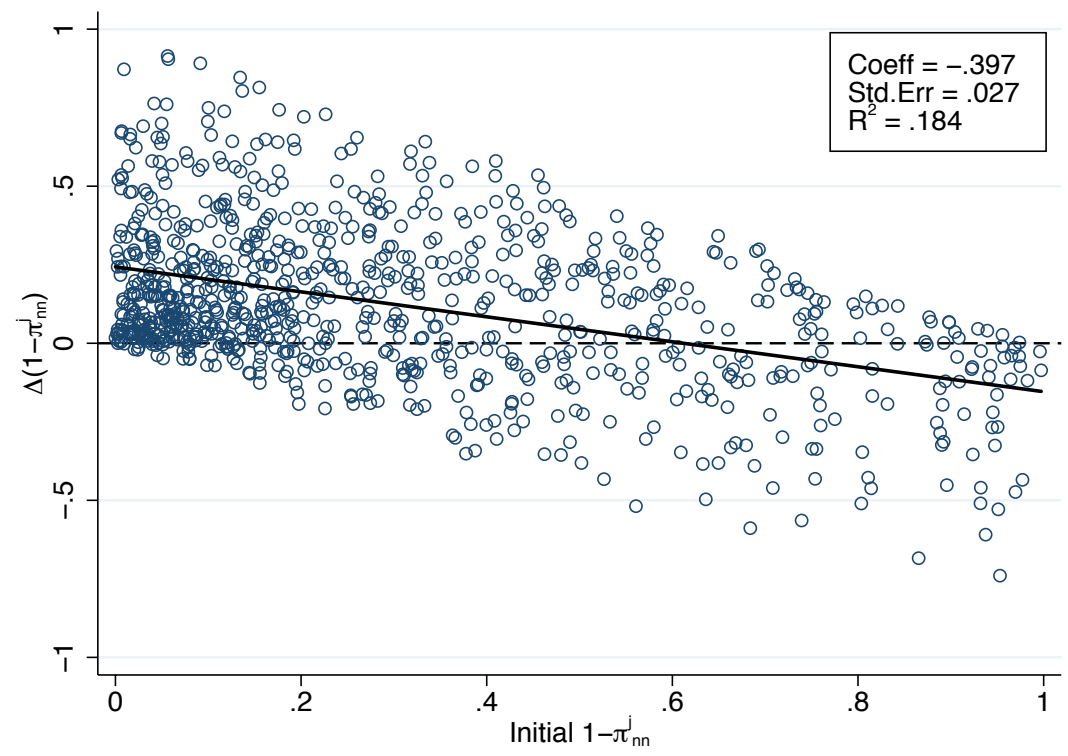

(a) Initial Import Shares and Changes in Import Shares

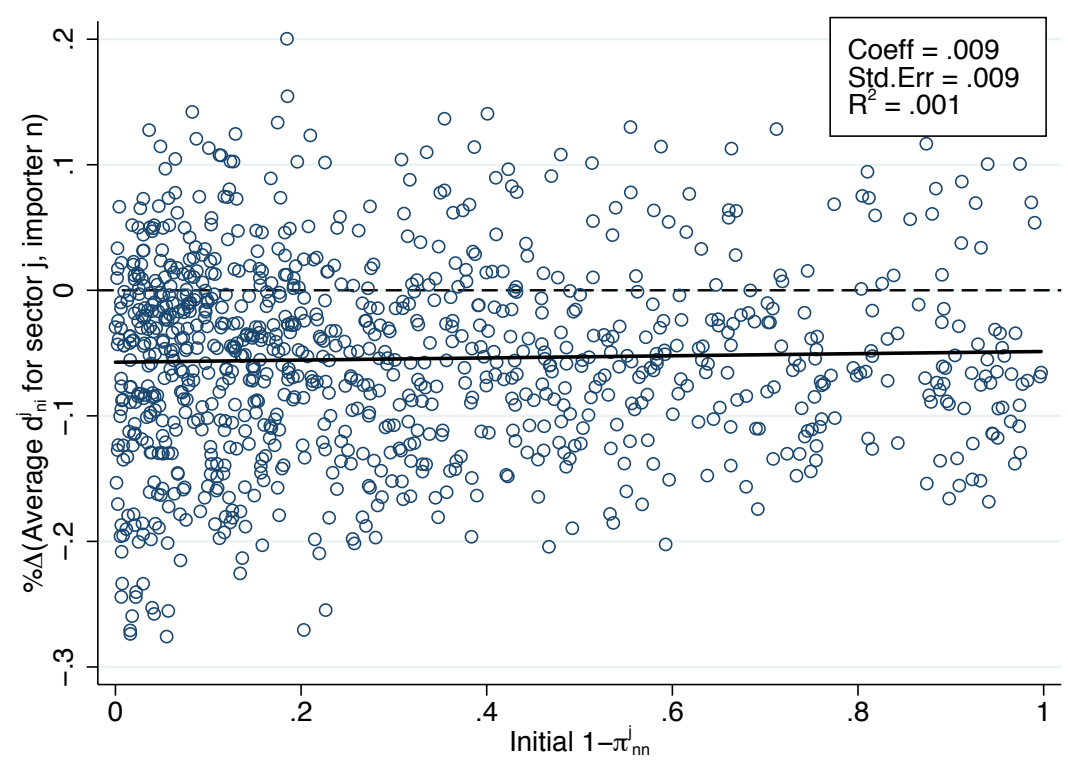

(b) Initial Import Shares and Changes in Trade Costs

Notes: This figure plots the change in the import share between the 1960s and 2000s $\Delta\left(1-\pi_{n n}^{j}\right)$ (top panel), and the percentage change in import-weighted average import costs $d_{n i}^{j}$ between the 1960 and the 2000s (bottom panel), against the import share of sector $j$ in country $n$ in the 1960s on the x-axis. The figure pools country-sectors. 
Table A1. Country Coverage

\begin{tabular}{|c|c|c|c|}
\hline Country & Period & Country & Period \\
\hline OECD & & Non-OECD & \\
\hline Australia & $1960 s-2000 s$ & Argentina & $1980 \mathrm{~s}-2000 \mathrm{~s}$ \\
\hline Austria & $1960 s-2000 s$ & Bangladesh & $1970 s-2000 s$ \\
\hline Belgium-Luxembourg & $1960 s-2000 s$ & Bolivia & $1960 \mathrm{~s}-2000 \mathrm{~s}$ \\
\hline Canada & $1960 s-2000 s$ & Brazil & $1980 s-2000 s$ \\
\hline Denmark & $1960 s-2000 s$ & Bulgaria & $1990 s-2000 s$ \\
\hline Finland & $1960 s-2000 s$ & Chile & $1960 s-2000 s$ \\
\hline France & $1960 s-2000 s$ & China & $1970 \mathrm{~s}-2000 \mathrm{~s}$ \\
\hline Germany & $1960 s-2000 s$ & Colombia & $1960 s-2000 s$ \\
\hline Greece & $1960 s-2000 s$ & Costa Rica & $1960 s-2000 s$ \\
\hline Iceland & $1960 s-2000 s$ & Czech Republic & $1990 \mathrm{~s}-2000 \mathrm{~s}$ \\
\hline Ireland & $1960 s-2000 s$ & Ecuador & $1960 s-2000 s$ \\
\hline Italy & $1960 s-2000 s$ & Egypt, Arab Rep. & $1960 s-2000 s$ \\
\hline Japan & $1960 s-2000 s$ & El Salvador & $1960 s-2000 s$ \\
\hline Netherlands & $1960 s-2000 s$ & Ethiopia & $1980 s-2000 s$ \\
\hline New Zealand & $1960 s-2000 s$ & Fiji & $1960 s-2000 s$ \\
\hline Norway & $1960 s-2000 s$ & Ghana & $1960 s-2000 s$ \\
\hline Portugal & $1960 s-2000 s$ & Guatemala & $1960 s-2000 s$ \\
\hline Spain & $1960 s-2000 s$ & Honduras & $1960 s-2000 s$ \\
\hline Sweden & $1960 s-2000 s$ & Hungary & $1990 s-2000 s$ \\
\hline Switzerland & $1980 s-2000 s$ & India & $1960 s-2000 s$ \\
\hline United Kingdom & $1960 s-2000 s$ & Indonesia & $1960 s-2000 s$ \\
\hline \multirow{29}{*}{ United States } & $1960 s-2000 s$ & Israel & $1960 s-2000 s$ \\
\hline & & Jordan & $1960 s-2000 s$ \\
\hline & & Kazakhstan & $1990 \mathrm{~s}-2000 \mathrm{~s}$ \\
\hline & & Kenya & $1960 s-2000 s$ \\
\hline & & Korea, Rep. & $1960 s-2000 s$ \\
\hline & & Malaysia & $1960 s-2000 s$ \\
\hline & & Mauritius & $1960 s-2000 s$ \\
\hline & & Mexico & $1960 s-2000 s$ \\
\hline & & Nigeria & $1960 s-2000 s$ \\
\hline & & Pakistan & $1960 s-2000 s$ \\
\hline & & Peru & $1980 s-2000 s$ \\
\hline & & Philippines & $1960 s-2000 s$ \\
\hline & & Poland & $1990 \mathrm{~s}-2000 \mathrm{~s}$ \\
\hline & & Romania & $1990 \mathrm{~s}-2000 \mathrm{~s}$ \\
\hline & & Russian Federation & $1990 s-2000 s$ \\
\hline & & Senegal & $1970 s-2000 s$ \\
\hline & & Slovak Republic & $1990 s-2000 s$ \\
\hline & & Slovenia & $1990 s-2000 s$ \\
\hline & & South Africa & $1960 s-2000 s$ \\
\hline & & Sri Lanka & $1960 \mathrm{~s}-2000 \mathrm{~s}$ \\
\hline & & Taiwan Province of China & $1970 s-2000 s$ \\
\hline & & Tanzania & $1960 s-2000 s$ \\
\hline & & Thailand & $1960 s-2000 s$ \\
\hline & & Trinidad and Tobago & $1960 s-2000 s$ \\
\hline & & Turkey & $1960 s-2000 s$ \\
\hline & & Ukraine & $1990 s-2000 s$ \\
\hline & & Uruguay & $1960 s-2000 s$ \\
\hline & & Venezuela, RB & $1960 s-2000 s$ \\
\hline & & Vietnam & $1990 s-2000 s$ \\
\hline
\end{tabular}

Notes: This table reports the countries in the sample and the decades for which data are available for each country. 
Table A2. Sectors

\begin{tabular}{|c|c|c|c|c|c|}
\hline ISIC code & Sector Name & $\alpha_{j}$ & $\overline{\bar{\beta}}$ & $\gamma_{J+1, j}$ & $\omega_{j}$ \\
\hline 15 & Food and Beverages & 0.315 & 0.281 & 0.300 & 0.155 \\
\hline 16 & Tobacco Products & 0.264 & 0.520 & 0.527 & 0.026 \\
\hline 17 & Textiles & 0.467 & 0.371 & 0.295 & 0.016 \\
\hline 18 & Wearing Apparel, Fur & 0.493 & 0.377 & 0.319 & 0.124 \\
\hline 19 & Leather, Leather Products, Footwear & 0.485 & 0.359 & 0.329 & 0.025 \\
\hline 20 & Wood Products (Excl. Furniture) & 0.452 & 0.372 & 0.288 & 0.007 \\
\hline 21 & Paper and Paper Products & 0.366 & 0.344 & 0.386 & 0.010 \\
\hline 22 & Printing and Publishing & 0.484 & 0.469 & 0.407 & 0.005 \\
\hline 23 & Coke, Refined Petroleum Products, Nuclear Fuel & 0.244 & 0.243 & 0.245 & 0.087 \\
\hline 24 & Chemical and Chemical Products & 0.308 & 0.373 & 0.459 & 0.006 \\
\hline 25 & Rubber and Plastics Products & 0.385 & 0.387 & 0.345 & 0.011 \\
\hline 26 & Non-Metallic Mineral Products & 0.365 & 0.459 & 0.479 & 0.076 \\
\hline 27 & Basic Metals & 0.381 & 0.299 & 0.443 & 0.002 \\
\hline 28 & Fabricated Metal Products & 0.448 & 0.398 & 0.363 & 0.014 \\
\hline $29 \mathrm{C}$ & Office, Accounting, Computing, and Other Mach. & 0.473 & 0.390 & 0.388 & 0.070 \\
\hline $31 \mathrm{~A}$ & Electrical Machinery, Communication Equipment & 0.405 & 0.380 & 0.416 & 0.041 \\
\hline 33 & Medical, Precision, and Optical Instruments & 0.456 & 0.428 & 0.441 & 0.059 \\
\hline $34 \mathrm{~A}$ & Transport Equipment & 0.464 & 0.343 & 0.286 & 0.188 \\
\hline 36 & Furniture and Other Manufacturing & 0.460 & 0.407 & 0.395 & 0.080 \\
\hline \multirow[t]{4}{*}{$4 \mathrm{~A}$} & Nontradeables & 0.561 & 0.651 & 0.772 & \\
\hline & Mean & 0.414 & 0.393 & 0.394 & 0.053 \\
\hline & Min & 0.244 & 0.243 & 0.245 & 0.002 \\
\hline & Max & 0.561 & 0.651 & 0.772 & 0.188 \\
\hline
\end{tabular}

Notes: This table reports the sectors used in the analysis. The classification corresponds to the ISIC Revision 3 2-digit, aggregated further due to data availability. $\alpha_{j}$ is the value-added based labor intensity; $\beta_{j}$ is the share of value added in total output; $\gamma_{J+1, j}$ is the share of nontradeable inputs in total intermediate inputs; $\omega_{j}$ is the taste parameter for tradeable sector $j$, estimated using the procedure described in Section 3.2. Variable definitions and sources are described in detail in the text. 
Table A3. Country-by-Country Estimates of Relative Convergence, 1960s to 2000s

\begin{tabular}{|c|c|c|c|c|c|}
\hline Country & 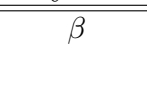 & s.e. & Obs. & $\mathrm{R}^{2}$ & $\begin{array}{c}\text { Speed of Convergence, } \\
\text { by decade }\end{array}$ \\
\hline United Kingdom & $-0.412^{* *}$ & 0.186 & 19 & 0.258 & 0.133 \\
\hline Austria & -0.551 & 0.381 & 19 & 0.144 & 0.200 \\
\hline Belgium-Luxembourg & $-0.760 * * *$ & 0.136 & 19 & 0.608 & 0.356 \\
\hline Denmark & $-0.695^{* * *}$ & 0.194 & 19 & 0.443 & 0.297 \\
\hline France & $-0.817 * * *$ & 0.198 & 19 & 0.603 & 0.424 \\
\hline Germany & $-0.644^{* * *}$ & 0.116 & 19 & 0.558 & 0.258 \\
\hline Italy & $-0.532 * * *$ & 0.145 & 19 & 0.442 & 0.190 \\
\hline Netherlands & $-0.583^{* *}$ & 0.219 & 19 & 0.295 & 0.219 \\
\hline Norway & $-0.985^{* * *}$ & 0.137 & 19 & 0.725 & 1.047 \\
\hline Sweden & $-0.668^{* * *}$ & 0.165 & 18 & 0.482 & 0.276 \\
\hline Canada & -0.147 & 0.230 & 19 & 0.016 & 0.040 \\
\hline Japan & $-0.885^{* * *}$ & 0.164 & 18 & 0.698 & 0.540 \\
\hline Finland & $-0.720 * * *$ & 0.166 & 19 & 0.641 & 0.318 \\
\hline Greece & $-0.299^{* * *}$ & 0.086 & 19 & 0.318 & 0.089 \\
\hline Iceland & $-0.425^{*}$ & 0.229 & 15 & 0.295 & 0.138 \\
\hline Ireland & $-0.706^{*}$ & 0.335 & 19 & 0.274 & 0.306 \\
\hline Portugal & $-0.490 * * *$ & 0.146 & 19 & 0.352 & 0.168 \\
\hline Spain & $-0.493^{* * *}$ & 0.102 & 19 & 0.558 & 0.170 \\
\hline Turkey & $-0.445^{* * *}$ & 0.104 & 18 & 0.591 & 0.147 \\
\hline Australia & $-0.567 * * *$ & 0.150 & 19 & 0.499 & 0.209 \\
\hline New Zealand & $-0.247^{* *}$ & 0.106 & 19 & 0.301 & 0.071 \\
\hline South Africa & -0.014 & 0.229 & 18 & 0.000 & 0.004 \\
\hline Bolivia & $-0.266^{* *}$ & 0.102 & 17 & 0.260 & 0.077 \\
\hline Chile & -0.143 & 0.104 & 19 & 0.065 & 0.039 \\
\hline Colombia & -0.237 & 0.139 & 19 & 0.180 & 0.067 \\
\hline Costa Rica & $-0.511^{* * *}$ & 0.165 & 17 & 0.394 & 0.179 \\
\hline Ecuador & $-0.245^{* * *}$ & 0.072 & 19 & 0.323 & 0.070 \\
\hline El Salvador & -0.247 & 0.145 & 18 & 0.103 & 0.071 \\
\hline Honduras & $-0.415^{* *}$ & 0.167 & 17 & 0.288 & 0.134 \\
\hline Mexico & $-0.462^{* *}$ & 0.161 & 13 & 0.331 & 0.155 \\
\hline Uruguay & $-0.319^{* *}$ & 0.116 & 19 & 0.252 & 0.096 \\
\hline Venezuela, RB & $-0.401 * * *$ & 0.133 & 19 & 0.463 & 0.128 \\
\hline Trinidad and Tobago & -0.191 & 0.376 & 17 & 0.034 & 0.053 \\
\hline Israel & $-0.457 * * *$ & 0.147 & 18 & 0.302 & 0.153 \\
\hline Jordan & $-0.476^{* *}$ & 0.188 & 18 & 0.252 & 0.161 \\
\hline Egypt, Arab Rep. & $-0.299^{* *}$ & 0.113 & 19 & 0.140 & 0.089 \\
\hline Sri Lanka & 0.039 & 0.171 & 19 & 0.003 & -0.009 \\
\hline India & $-0.249^{*}$ & 0.126 & 19 & 0.153 & 0.072 \\
\hline Indonesia & $-0.590^{* * *}$ & 0.099 & 16 & 0.706 & 0.223 \\
\hline Korea, Rep. & $-0.688^{* * *}$ & 0.110 & 19 & 0.780 & 0.291 \\
\hline Malaysia & $-0.584^{* * *}$ & 0.121 & 19 & 0.421 & 0.219 \\
\hline Pakistan & $-0.389^{* *}$ & 0.147 & 8 & 0.343 & 0.123 \\
\hline Philippines & $-0.558^{* * *}$ & 0.185 & 19 & 0.382 & 0.204 \\
\hline Thailand & $-0.898^{* * *}$ & 0.268 & 14 & 0.541 & 0.571 \\
\hline Ghana & 0.016 & 0.200 & 18 & 0.000 & -0.004 \\
\hline Kenya & -0.047 & 0.144 & 17 & 0.005 & 0.012 \\
\hline Mauritius & -0.275 & 0.201 & 15 & 0.120 & 0.080 \\
\hline Tanzania & $-0.533^{* * *}$ & 0.162 & 12 & 0.410 & 0.190 \\
\hline Fiji & $-0.299^{*}$ & 0.148 & 15 & 0.156 & 0.089 \\
\hline
\end{tabular}

Notes: Robust standard errors clustered in parentheses; ***: significant at $1 \%$; **: significant at $5 \%$; *: significant at $10 \%$. This table reports the results of regressing the growth of estimated technology parameter $\left(T_{n}^{j}\right)^{1 / \theta}$ over the period from the 1960 s to the 2000 s on its initial value, by country. The speed of convergence, per decade, is reported in the last column. Missing values are due to the convergence coefficient being larger than 1 . 
Table A4. Comparison of Estimates of $T_{n}^{j}$

\begin{tabular}{lccccc}
\hline Method & Mean & St. Dev. & Corr w/baseline & $\beta$ & s.e. $(\beta)$ \\
& & & & & \\
Baseline & 0.737 & 0.275 &.. & $-0.517^{* * *}$ & $(0.044)$ \\
& & & & & \\
Additional gravity & 0.728 & 0.270 & 0.999 & $-0.518^{* * *}$ & $(0.045)$ \\
Poisson & 0.720 & 0.271 & 0.969 & $-0.534^{* * *}$ & $(0.046)$ \\
$i m_{n t}^{j}$ in $d_{n i t}^{j}$ & 0.527 & 0.240 & 0.890 & $-0.339^{* * *}$ & $(0.051)$ \\
& & & & & \\
$r:$ Caselli-Feyrer & 0.702 & 0.295 & 0.989 & $-0.487^{* * *}$ & $(0.046)$ \\
$r:$ Euler & 0.694 & 0.265 & 0.954 & $-0.539^{* * *}$ & $(0.047)$ \\
$r:$ Direct & 0.744 & 0.273 & 0.910 & $-0.541^{* * *}$ & $(0.145)$ \\
$r:$ Fin. Integration & 0.682 & 0.264 & 0.960 & $-0.519^{* * *}$ & $(0.046)$ \\
& & & & & \\
Country-Specific IO & 0.766 & 0.267 & 0.987 & $-0.480^{* * *}$ & $(0.042)$ \\
Country-Specific IO, $\alpha, \beta$ & 0.805 & 0.272 & 0.903 & $-0.646^{* * *}$ & $(0.043)$ \\
& & & & & \\
$\theta=4$ & 0.726 & 0.352 & 0.942 & $-0.600^{* * *}$ & $(0.045)$ \\
$\theta$ Sector-Specific & 0.749 & 0.350 & 0.870 & $-0.691^{* * *}$ & $(0.047)$ \\
\hline
\end{tabular}

Notes: This table the results of comparing the baseline estimates of $T_{n}^{j}$ to alternative estimation approaches. The first and second columns report the mean and the standard deviation of $\left(T_{n}^{j}\right)^{1 / \theta}$ relative to the US. The third column reports the correlation between the baseline $\left(T_{n}^{j}\right)^{1 / \theta}$ relative to the US and the alternative estimate. The fourth and fifth columns report the coefficient and standard errors from estimating the convergence regression (10) using each set of $\left(T_{n}^{j}\right)^{1 / \theta}$ estimates. 
Table A5. Zero Trade Observations: Model vs. Data

\begin{tabular}{lcccccc}
\hline \hline Sector Name & ISIC code & $1960 \mathrm{~s}$ & $1970 \mathrm{~s}$ & $1980 \mathrm{~s}$ & $1990 \mathrm{~s}$ & $2000 \mathrm{~s}$ \\
& & & & & & \\
All Sectors Combined & & 0.007 & 0.006 & 0.006 & 0.001 & 0.009 \\
& & & & & & \\
& 15 & 0.000 & 0.000 & 0.000 & 0.000 & 0.000 \\
Food and Beverages & 16 & 0.075 & 0.100 & 0.015 & 0.015 & 0.026 \\
Tobacco Products & 17 & 0.000 & 0.000 & 0.000 & 0.002 & 0.005 \\
Textiles & 18 & 0.011 & 0.015 & 0.000 & 0.000 & 0.004 \\
Wearing Apparel, Fur & 19 & 0.011 & 0.016 & 0.028 & 0.001 & 0.031 \\
Leather, Leather Products, Footwear & 20 & 0.001 & 0.000 & 0.000 & 0.000 & 0.013 \\
Wood Products (Excl. Furniture) & 21 & 0.000 & 0.000 & 0.000 & 0.000 & 0.005 \\
Paper and Paper Products & 22 & 0.017 & 0.021 & 0.000 & 0.000 & 0.009 \\
Printing and Publishing & 23 & 0.003 & 0.003 & 0.023 & 0.008 & 0.011 \\
Coke, Refined Petroleum Products, Nuclear Fuel & 24 & 0.000 & 0.000 & 0.000 & 0.000 & 0.004 \\
Chemical and Chemical Products & 25 & 0.000 & 0.001 & 0.000 & 0.000 & 0.010 \\
Rubber and Plastics Products & 26 & 0.000 & 0.000 & 0.000 & 0.000 & 0.001 \\
Non-Metallic Mineral Products & 27 & 0.003 & 0.001 & 0.000 & 0.000 & 0.011 \\
Basic Metals & 28 & 0.000 & 0.000 & 0.036 & 0.000 & 0.020 \\
Fabricated Metal Products & $29 \mathrm{C}$ & 0.001 & 0.000 & 0.000 & 0.000 & 0.013 \\
Office, Accounting, Computing, and Other Mach. & $31 \mathrm{~A}$ & 0.000 & 0.000 & 0.000 & 0.000 & 0.011 \\
Electrical Machinery, Communication Equipment & 33 & 0.022 & 0.020 & 0.003 & 0.006 & 0.023 \\
Medical, Precision, and Optical Instruments & $34 \mathrm{~A}$ & 0.012 & 0.000 & 0.005 & 0.000 & 0.011 \\
Transport Equipment & 36 & 0.012 & 0.015 & 0.005 & 0.002 & 0.012 \\
Furniture and Other Manufacturing & & & & & & \\
\hline
\end{tabular}

Notes: This table reports the share of global absorption taken up by importer-exporter-sector observations for which actual imports are zero in the data. 
Table A6. Comparison to Measured TFP from STAN Database

\begin{tabular}{|c|c|c|c|c|c|}
\hline \multicolumn{6}{|c|}{ Panel A: Sector-by-Sector Rank Correlations } \\
\hline ISIC code & \multicolumn{3}{|c|}{ Sector Name } & Correlation & Countries \\
\hline 15 & \multicolumn{3}{|c|}{ Food and Beverages } & 0.8000 & 4 \\
\hline 16 & \multicolumn{3}{|c|}{ Tobacco Products } & 1.0000 & 4 \\
\hline 17 & \multicolumn{3}{|c|}{ Textiles } & 0.9000 & 5 \\
\hline 18 & \multicolumn{3}{|c|}{ Wearing Apparel, Fur } & 0.1000 & 5 \\
\hline 19 & \multicolumn{3}{|c|}{ Leather, Leather Products, Footwear } & -0.2000 & 5 \\
\hline 20 & \multicolumn{3}{|c|}{ Wood Products (Excl. Furniture) } & 0.4524 & 8 \\
\hline 21 & \multicolumn{3}{|c|}{ Paper and Paper Products } & 0.9429 & 6 \\
\hline 22 & \multicolumn{3}{|c|}{ Printing and Publishing } & 1.0000 & 6 \\
\hline 23 & \multicolumn{3}{|c|}{ Coke, Refined Petroleum Products, Nuclear Fuel } & 0.6000 & 6 \\
\hline 24 & \multicolumn{3}{|c|}{ Chemical and Chemical Products } & 0.7500 & 7 \\
\hline 25 & \multicolumn{3}{|c|}{ Rubber and Plastics Products } & 0.8095 & 8 \\
\hline 26 & \multicolumn{3}{|c|}{ Non-Metallic Mineral Products } & 0.6833 & 9 \\
\hline 27 & \multicolumn{3}{|c|}{ Basic Metals } & 0.6571 & 6 \\
\hline 28 & \multicolumn{3}{|c|}{ Fabricated Metal Products } & 0.9429 & 6 \\
\hline $29 \mathrm{C}$ & \multicolumn{3}{|c|}{ Office, Accounting, Computing, and Other Machinery } & 0.8095 & 8 \\
\hline $31 \mathrm{~A}$ & \multicolumn{3}{|c|}{ Electrical Machinery, Communication Equipment } & 1.0000 & 5 \\
\hline 33 & \multicolumn{3}{|c|}{ Medical, Precision, and Optical Instruments } & 0.7714 & 6 \\
\hline $34 \mathrm{~A}$ & \multicolumn{3}{|c|}{ Transport Equipment } & 0.4857 & 6 \\
\hline 36 & \multicolumn{3}{|c|}{ Furniture and Other Manufacturing } & 0.9000 & 5 \\
\hline \multicolumn{6}{|c|}{ Panel B: Fixed Effects Regression } \\
\hline \multicolumn{6}{|c|}{$\begin{array}{llll} & (1) & (2) & (3)\end{array}$} \\
\hline \multicolumn{6}{|c|}{ Dep. Var: Log Sectoral Productivity Implied by Sectoral Measured TFP } \\
\hline \multirow[t]{2}{*}{$\log \left(T_{n}^{j}\right)^{1 / \theta}$} & $0.656^{* * *}$ & $1.030^{* * *}$ & $0.532^{* *}$ & & \\
\hline & $(0.126)$ & $(0.126)$ & $(0.228)$ & & \\
\hline Observations & 115 & 115 & 115 & & \\
\hline R-squared & 0.137 & 0.556 & 0.885 & & \\
\hline Partial $\rho$ & 0.370 & 0.349 & 0.084 & & \\
\hline Sector FE & no & yes & yes & & \\
\hline Country FE & no & no & yes & & \\
\hline
\end{tabular}

Notes: This table reports the results of comparing the productivity estimates using the main procedure adopted in the paper $\left(\left(T_{n}^{j}\right)^{1 / \theta}\right)$ with TFP estimated directly using production data from the OECD STAN database. Panel A reports the Spearman rank correlations of the two alternative productivity measures by sector. Panel B reports the results of a fixed effects regression of directly measured TFP from STAN on $\left(T_{n}^{j}\right)^{1 / \theta}$. In Panel B, robust standard errors in parentheses; **: significant at 5\%; ***: significant at 1\%. "Partial $\rho$ " is the partial correlation between the right-hand side and the left-hand side variables, after netting out the fixed effects included in the column. 